\title{
Supporting Information \\ Copper-Catalyzed Oxirane-Opening Reaction with Aryl \\ Iodides and Se Powder
}

Lin Min $,{ }^{\dagger} \mathrm{Ge} \mathrm{Wu},{ }^{*}{ }^{\dagger}$ Miaochang Liu,${ }^{\dagger}$ Wenxia Gao, ${ }^{\dagger}$ Jinchang Ding, ${ }^{\dagger}$

Jiuxi Chen, ${ }^{\dagger}$ Xiaobo Huang, ${ }^{\dagger}$ and Huayue $\mathrm{Wu}^{*}{ }^{\dagger}{ }^{\dagger}$

$\uparrow$ College of Chemistry and Materials Engineering, Wenzhou University,

Wenzhou 325035, People's Republic of China

†School of Pharmacy, Wenzhou Medical University, Wenzhou, Zhejiang

325035, People's Republic of China

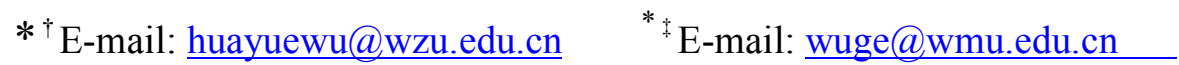

Table of Contents

(1) ${ }^{1} \mathrm{H},{ }^{13} \mathrm{C}$ and ${ }^{19} \mathrm{~F}$ NMR spectra of products.........S2-S43 
${ }^{1} \mathrm{H},{ }^{13} \mathrm{C}$ and ${ }^{19} \mathrm{~F}$ NMR spectra of products
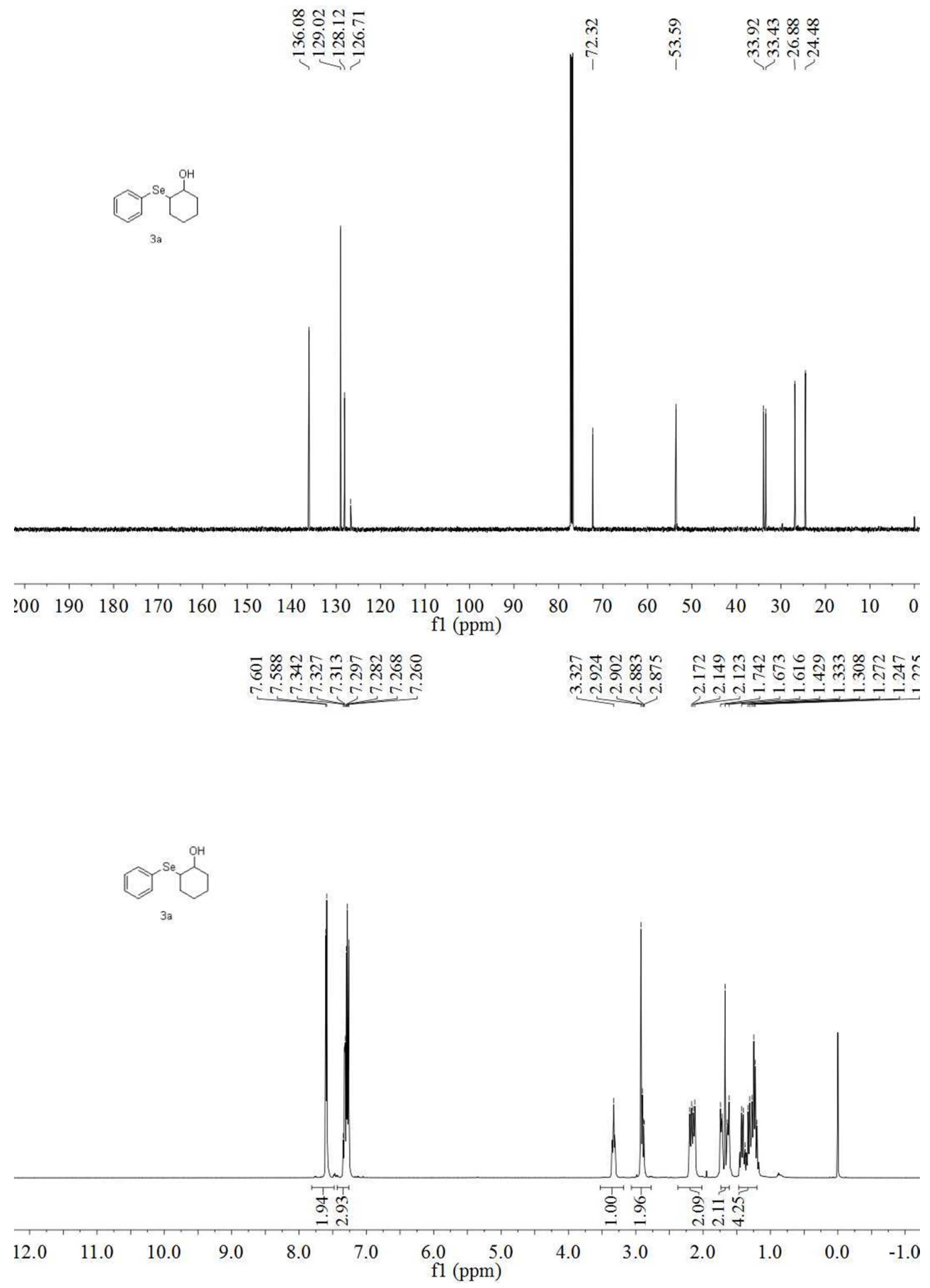

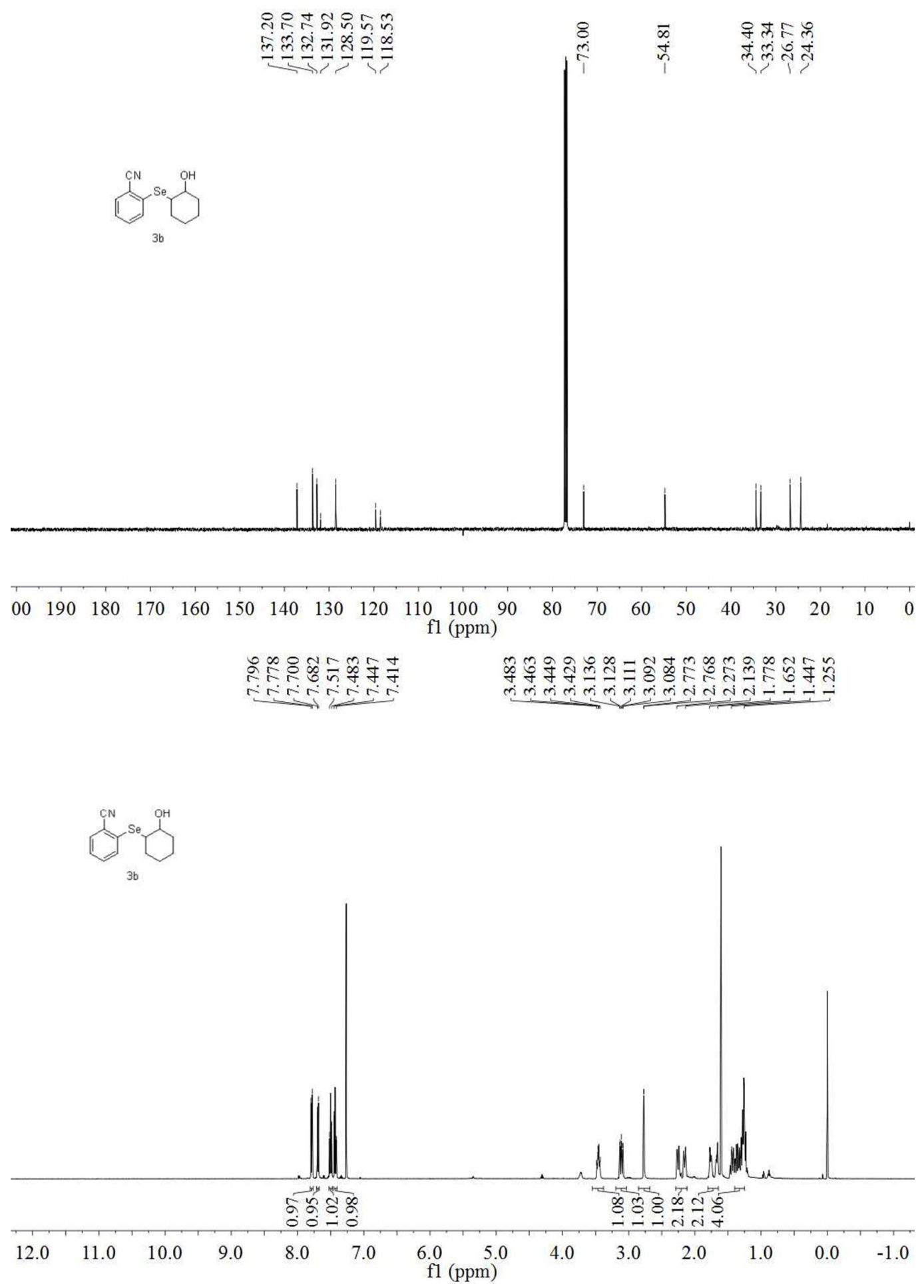


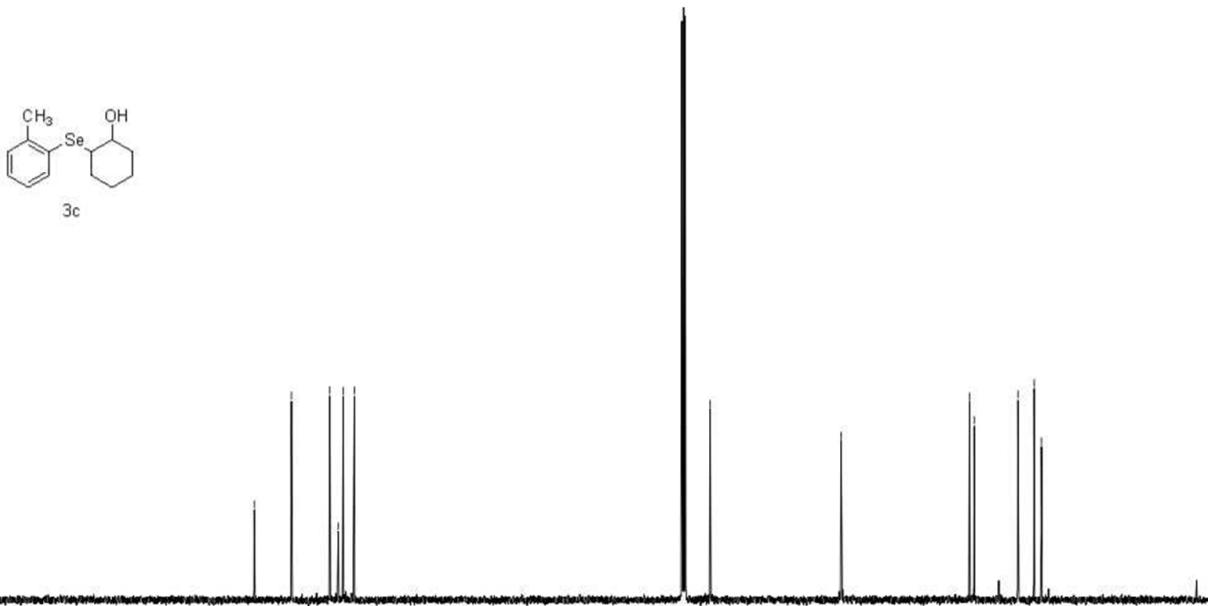

$3 \mathrm{c}$

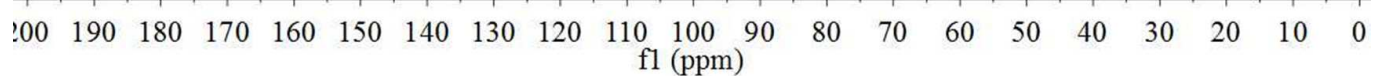

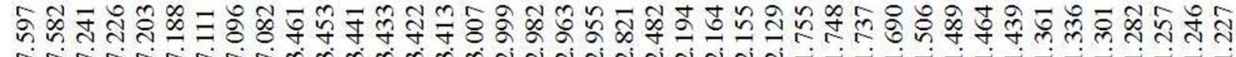
रrлm

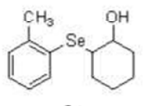



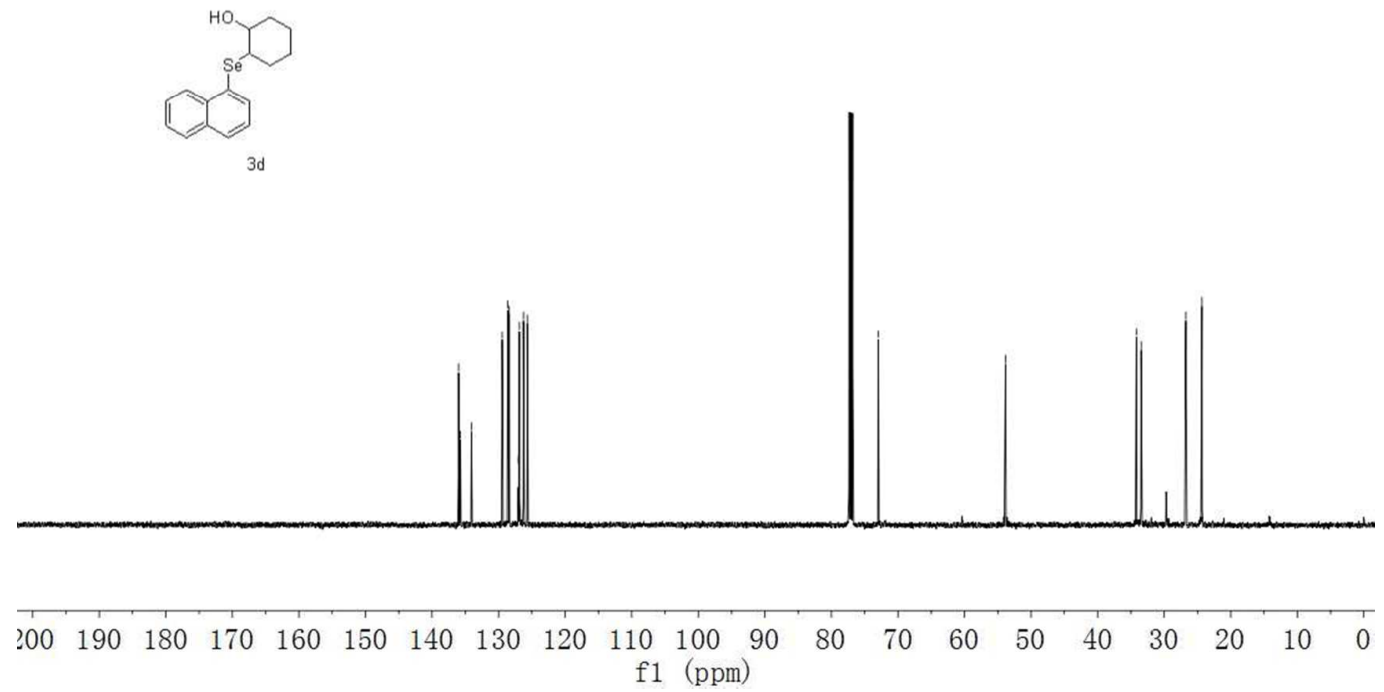

कृष

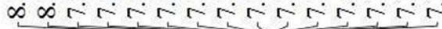

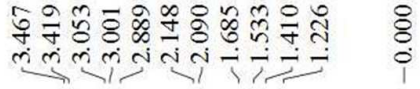
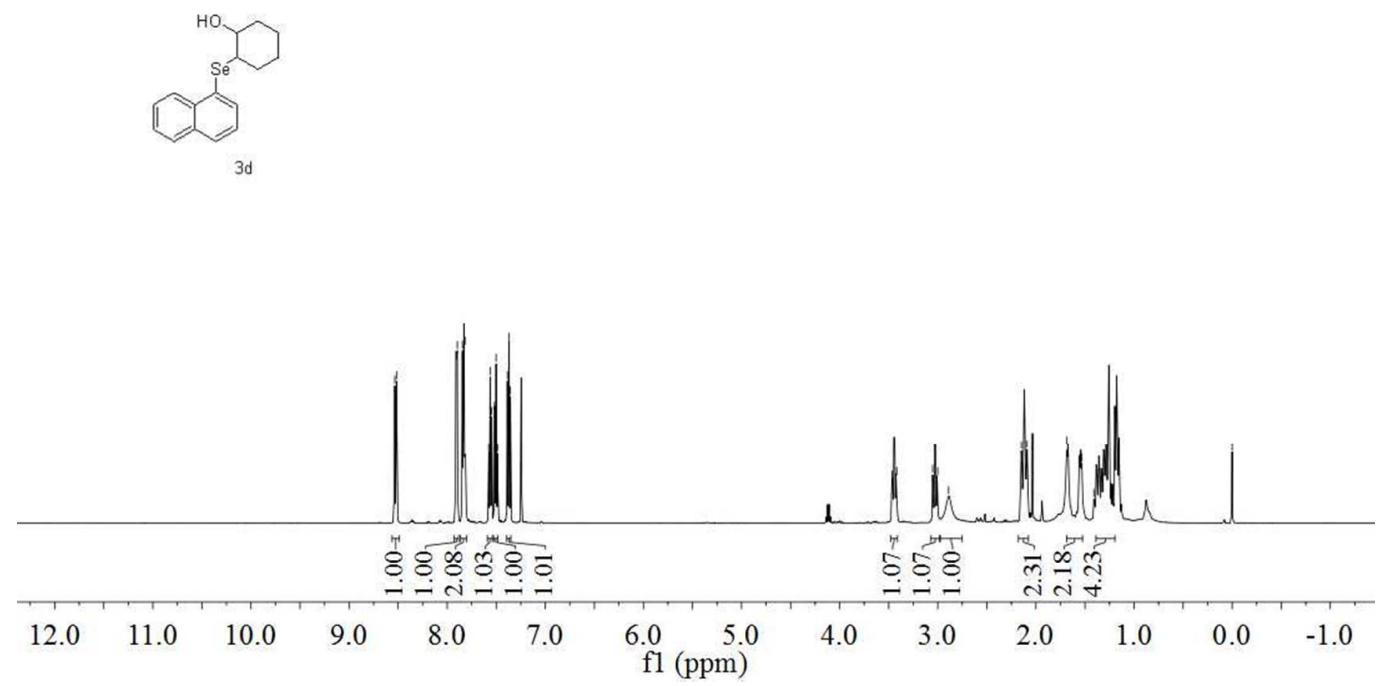


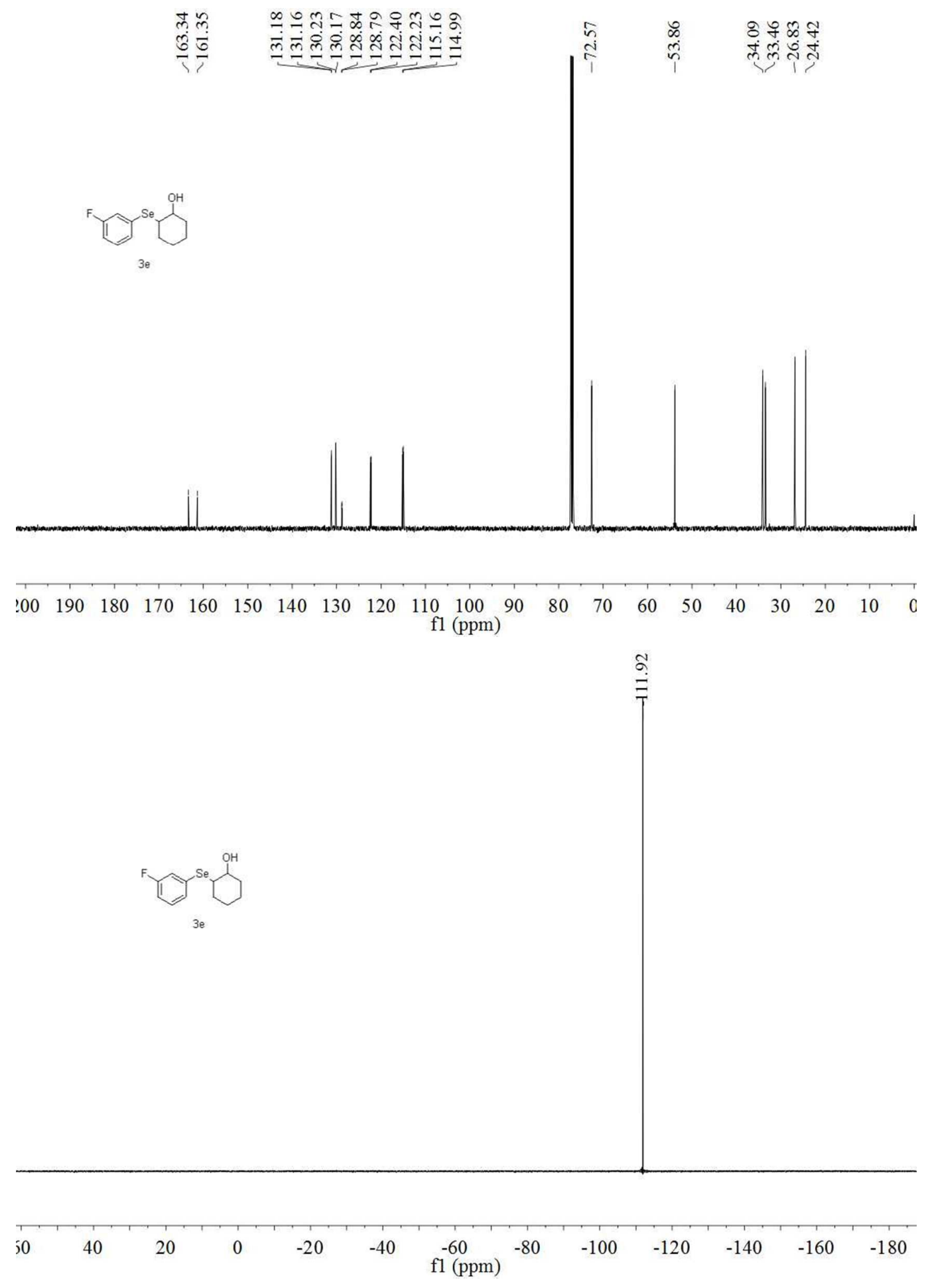




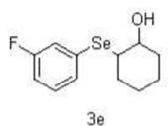

$3 e$
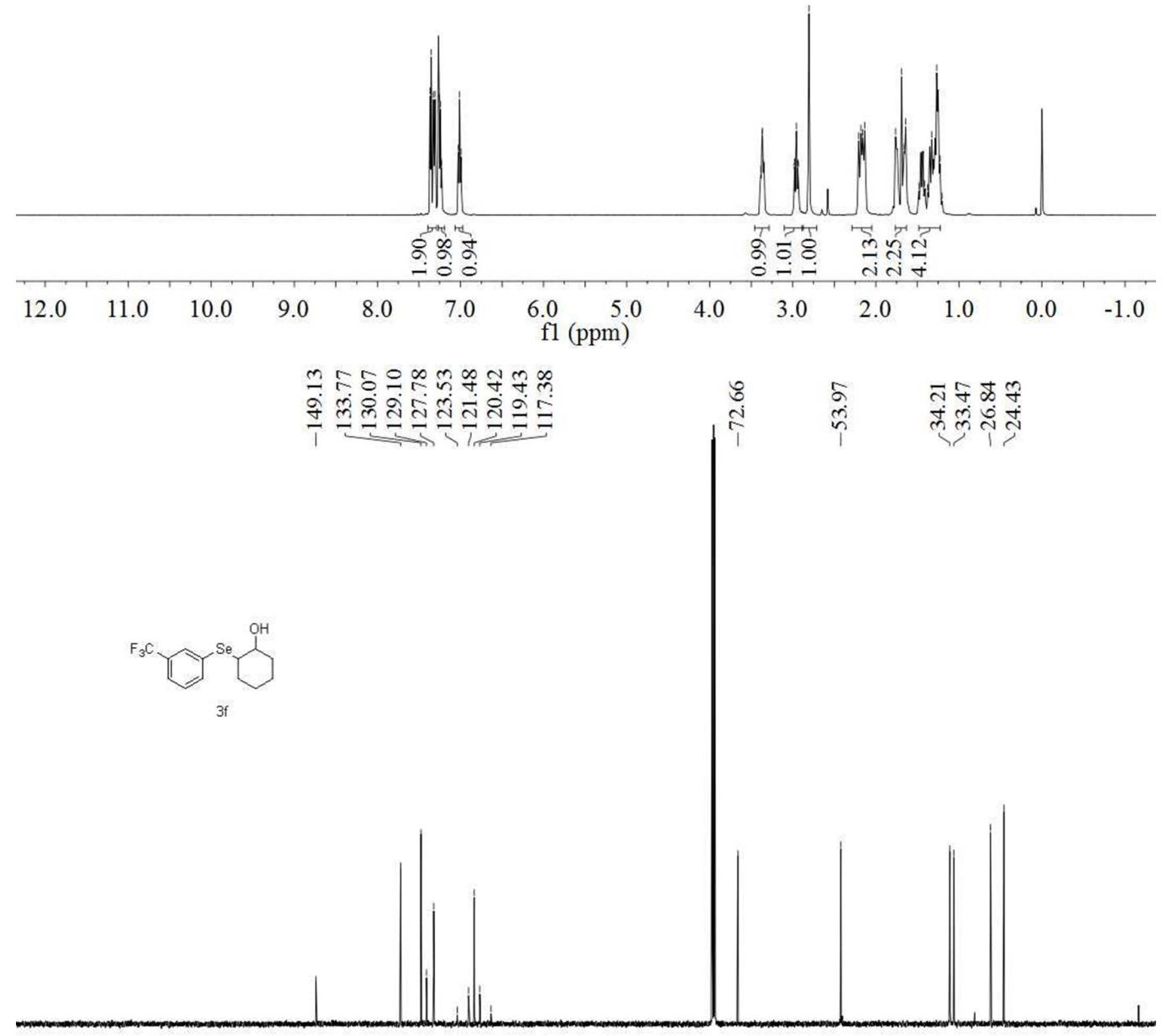

$\begin{array}{lllllllllllllllllllll}200 & 190 & 180 & 170 & 160 & 150 & 140 & 130 & 120 & 110 & 100 & 90 & 80 & 70 & 60 & 50 & 40 & 30 & 20 & 10 & 0\end{array}$ f1 (ppm) 


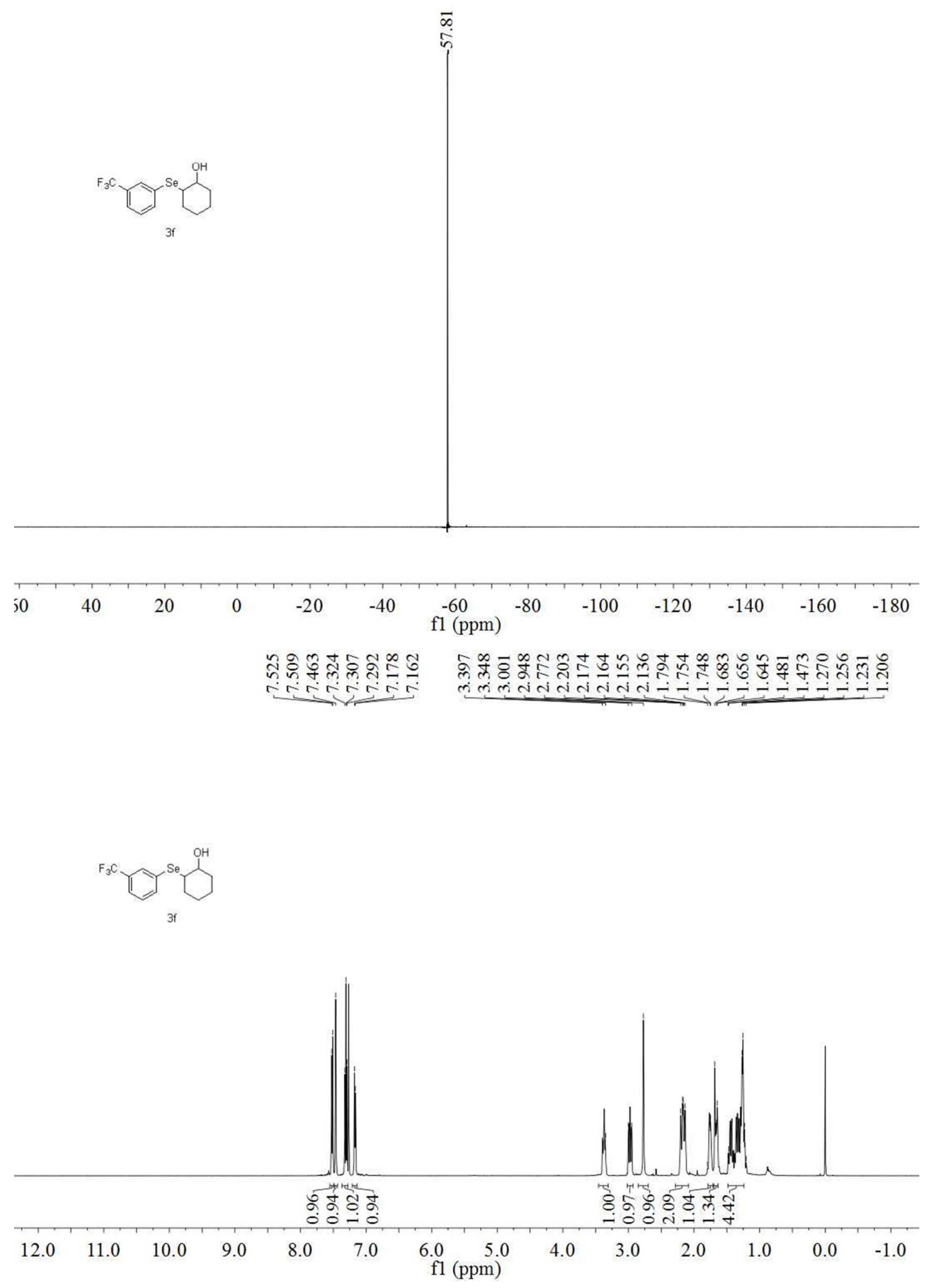




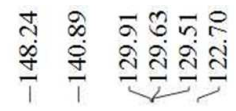

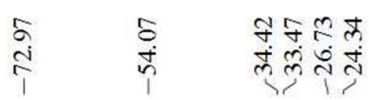
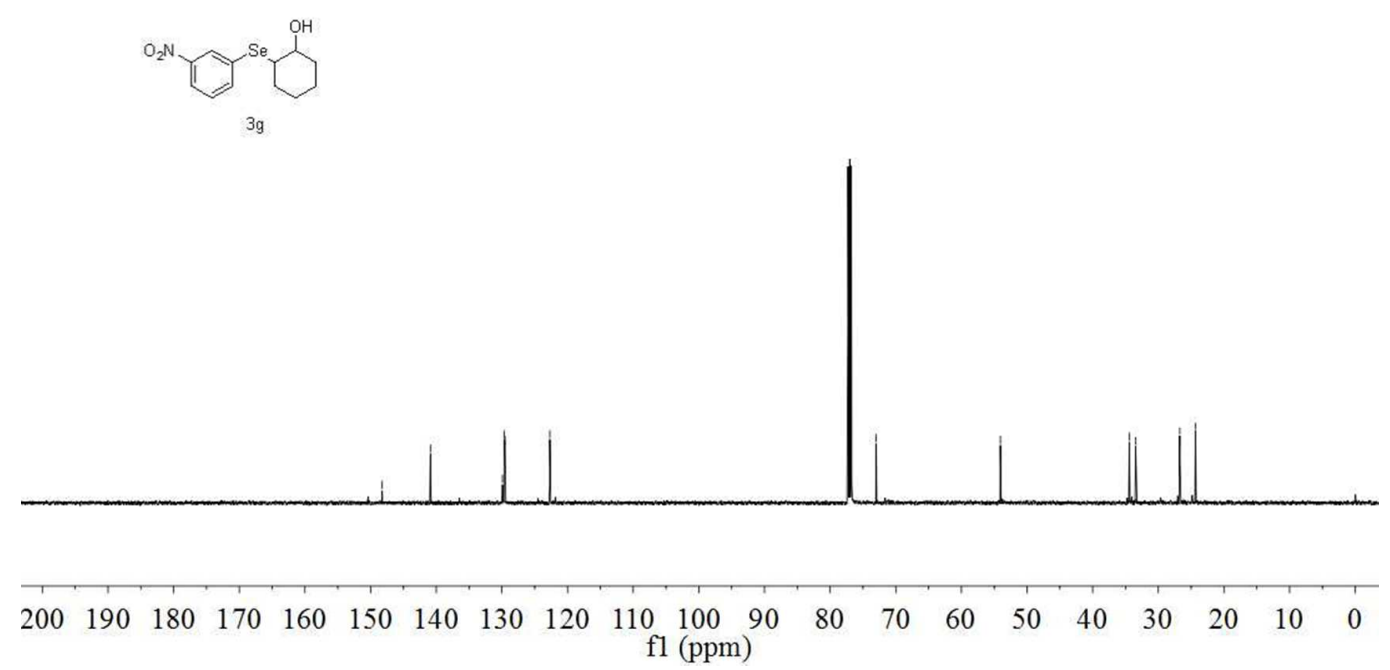

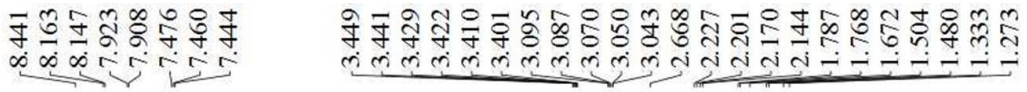

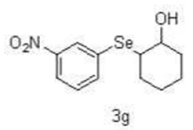

39

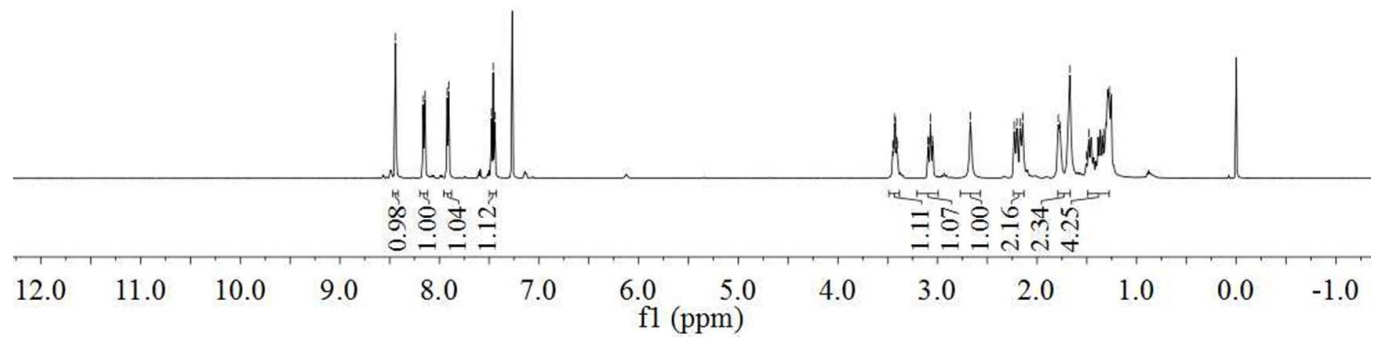



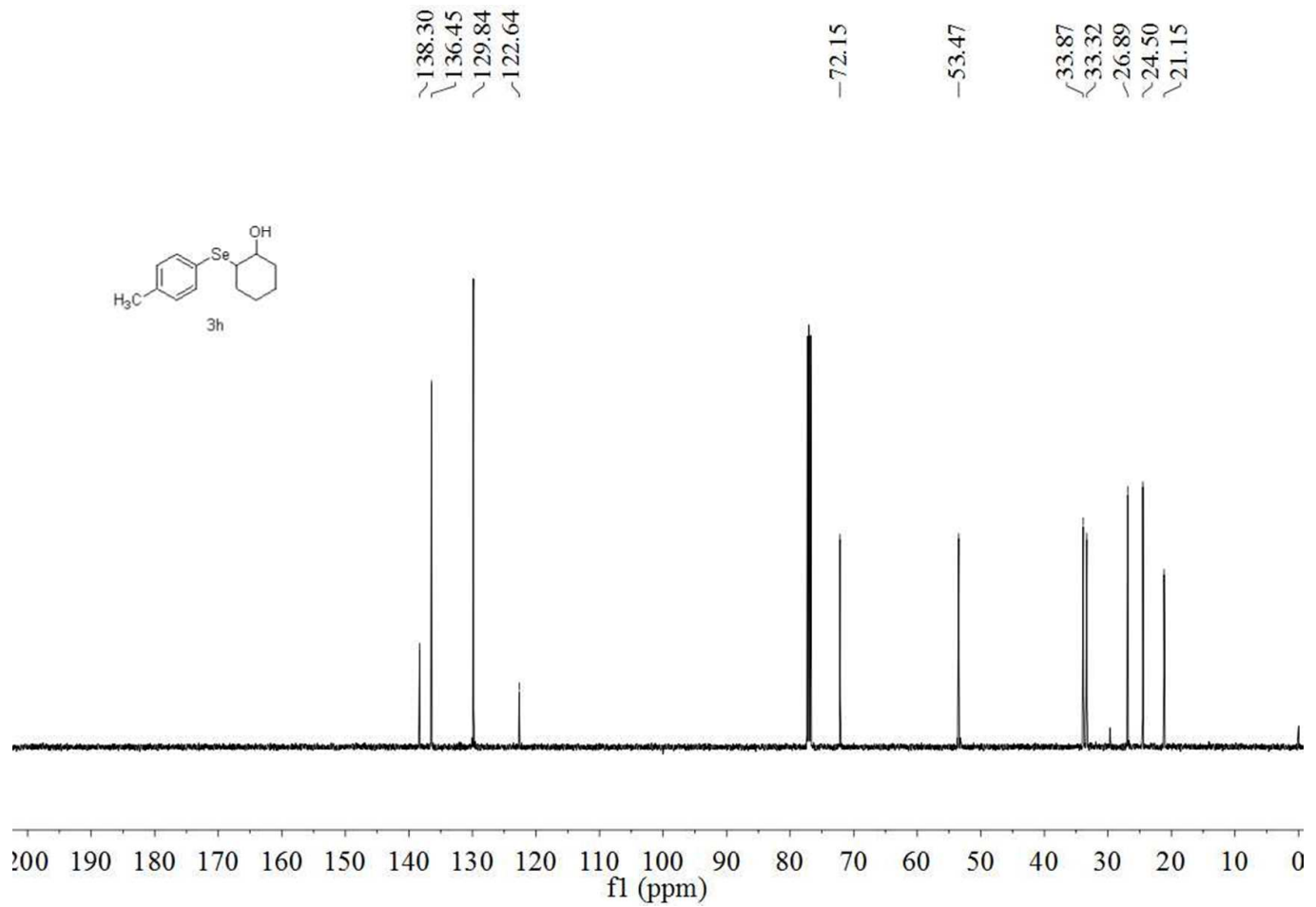

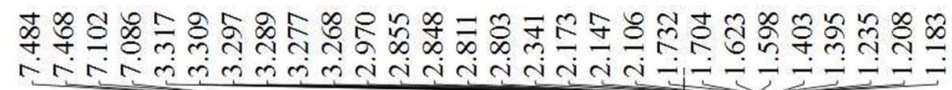

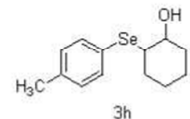

$3 \mathrm{~h}$

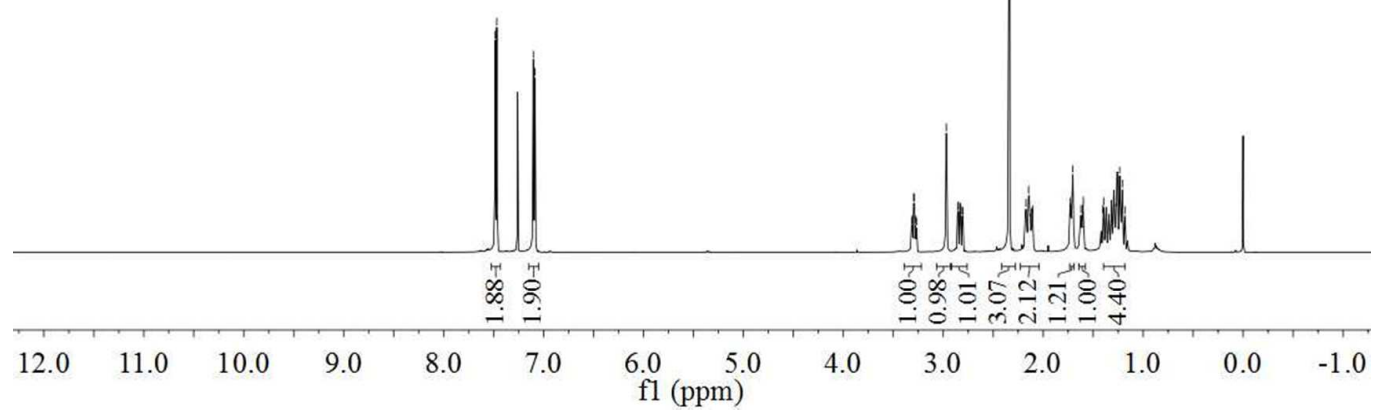



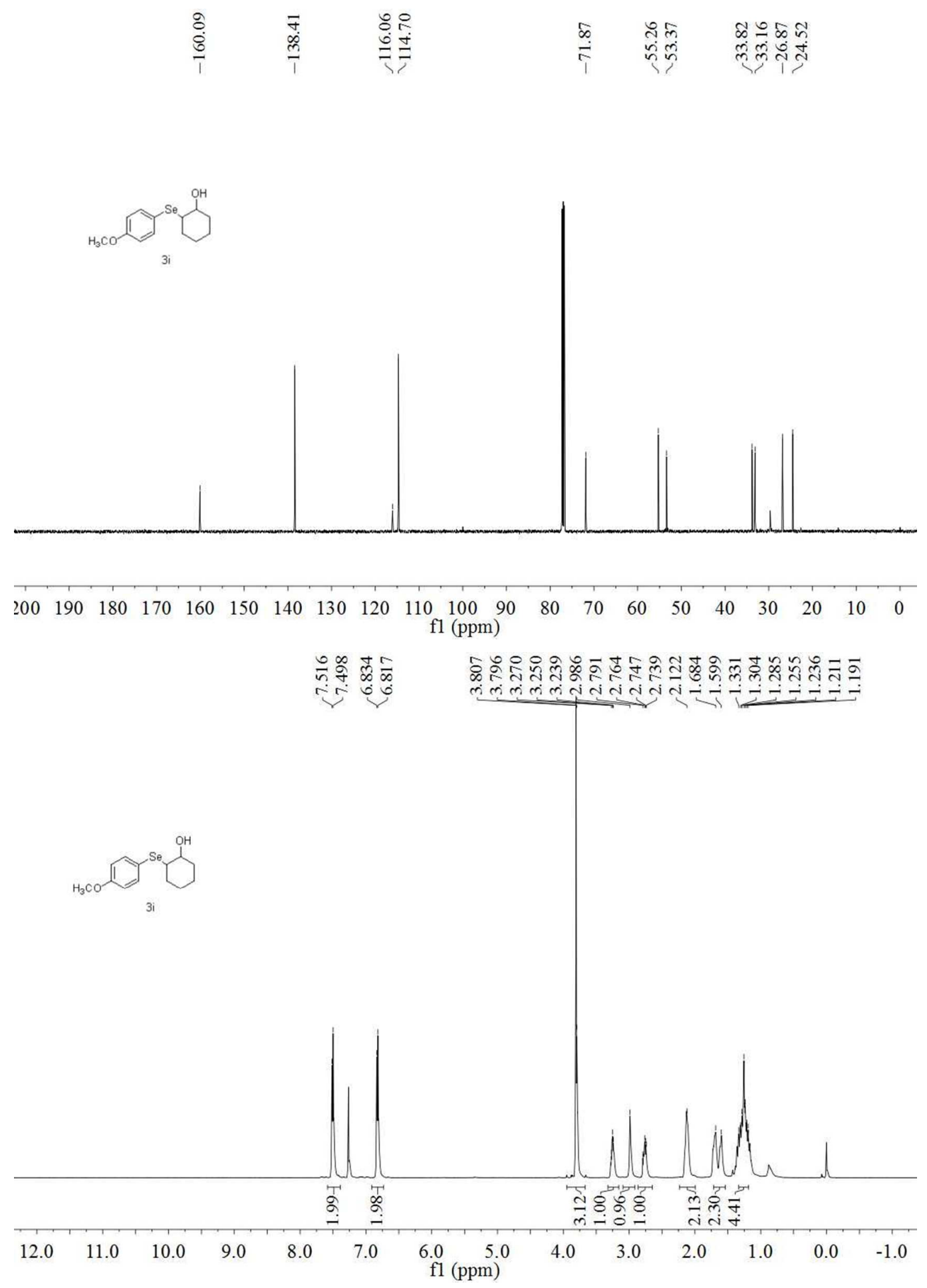

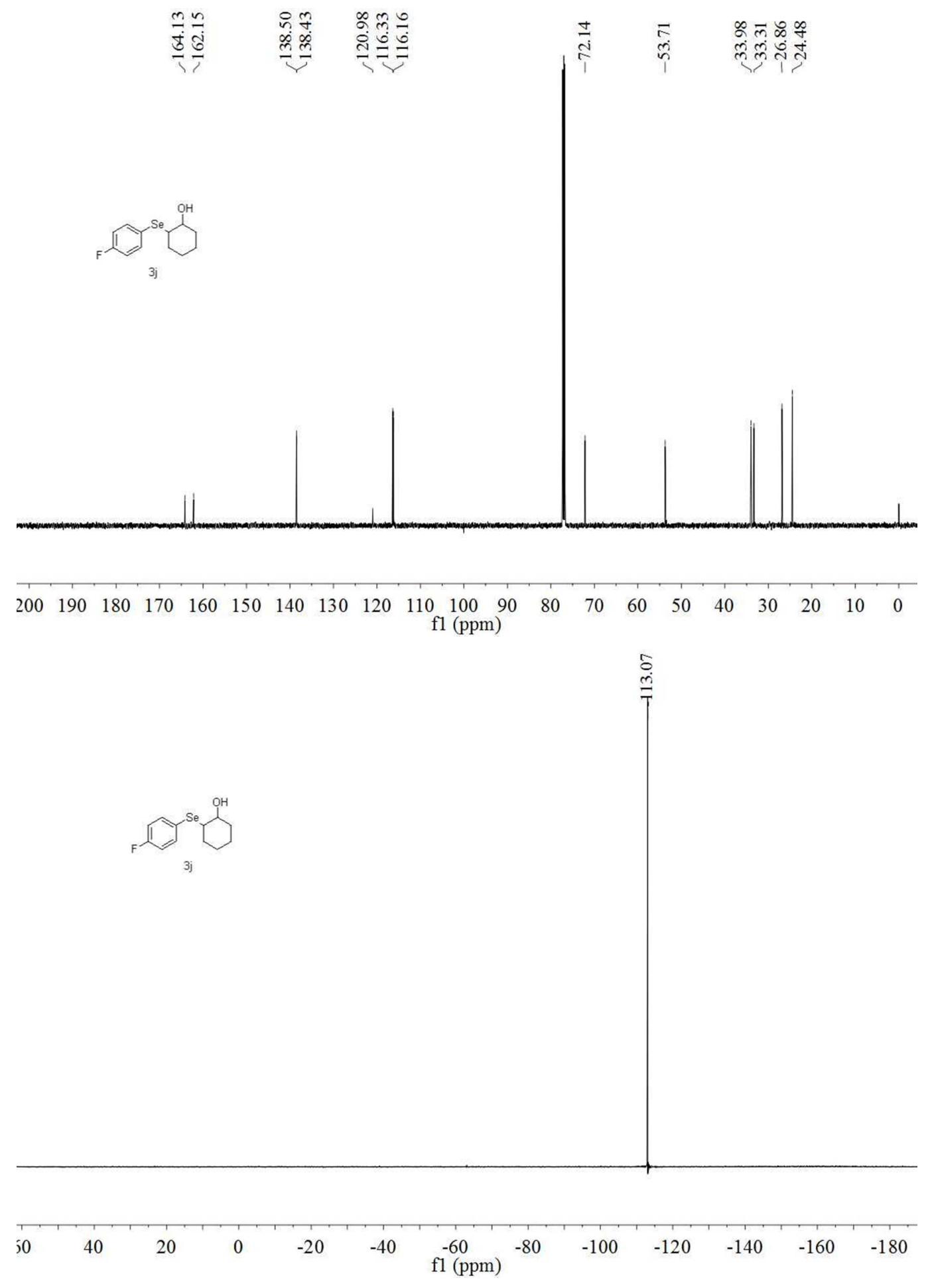

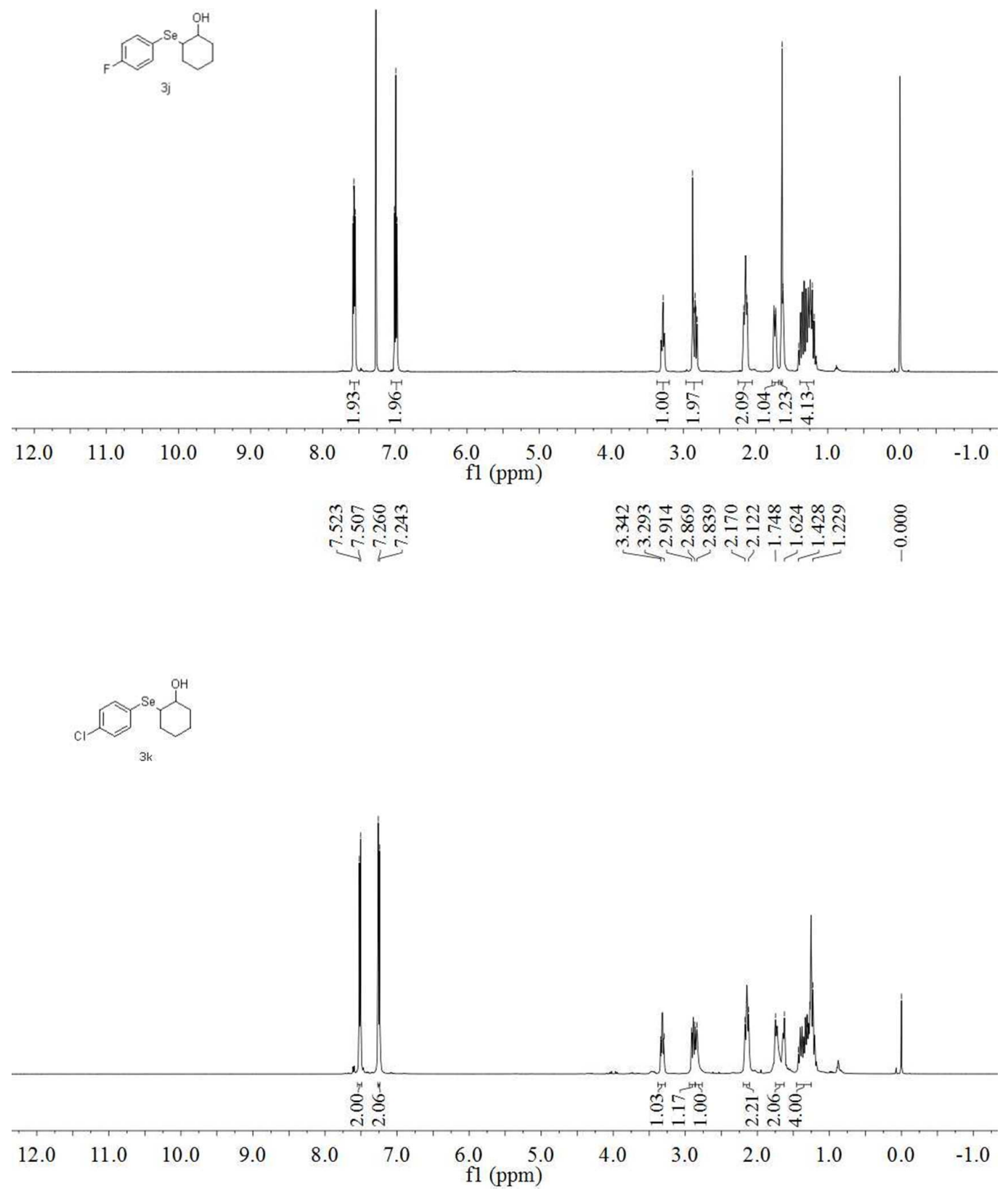


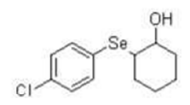

$3 k$

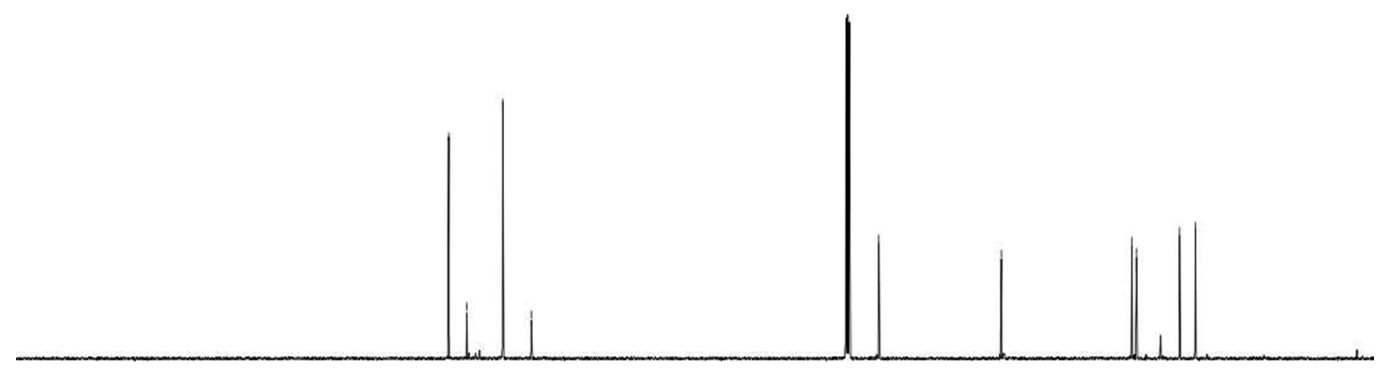

$\begin{array}{lllllllllllllllllllll}200 & 190 & 180 & 170 & 160 & 150 & 140 & 130 & 120 & 110 & 100 & 90 & 80 & 70 & 60 & 50 & 40 & 30 & 20 & 10 & 0\end{array}$ f1 (ppm)
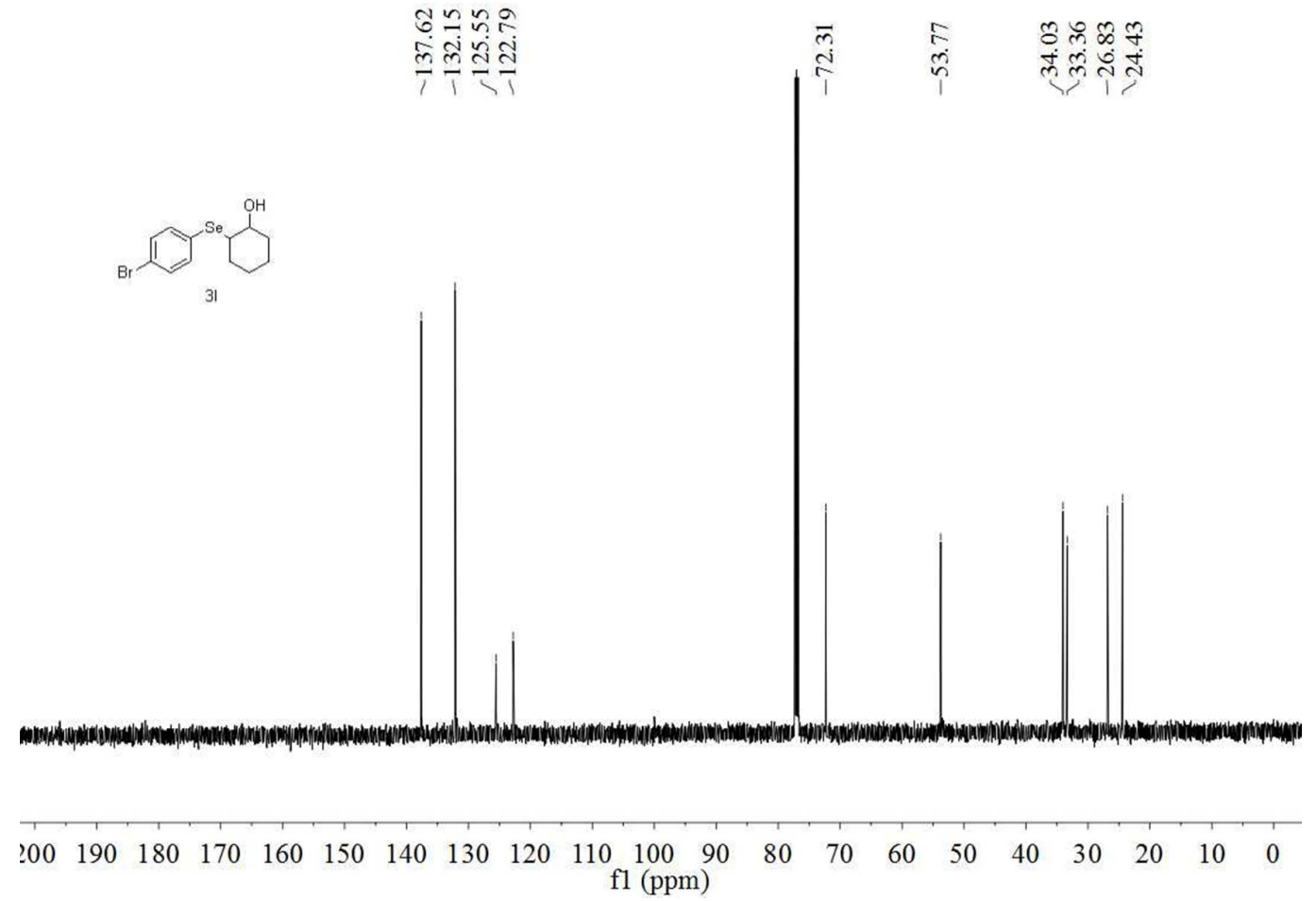

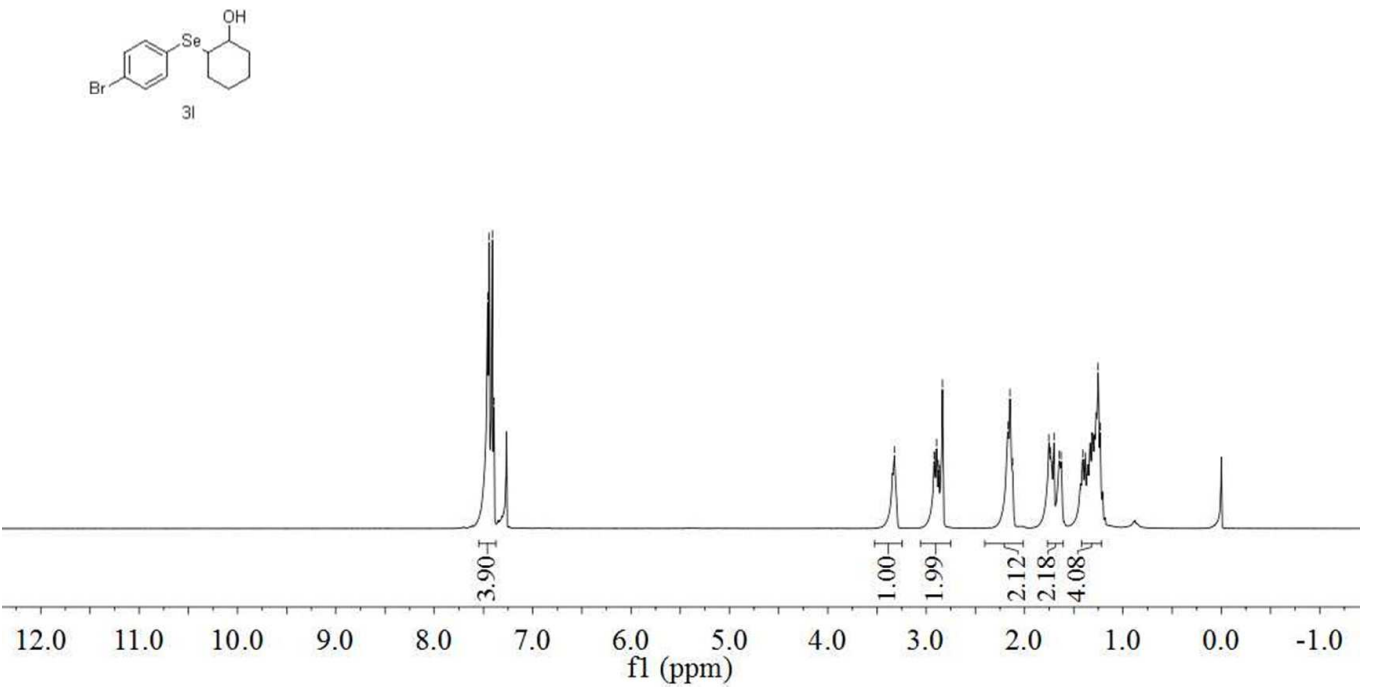

$\frac{n}{2}$
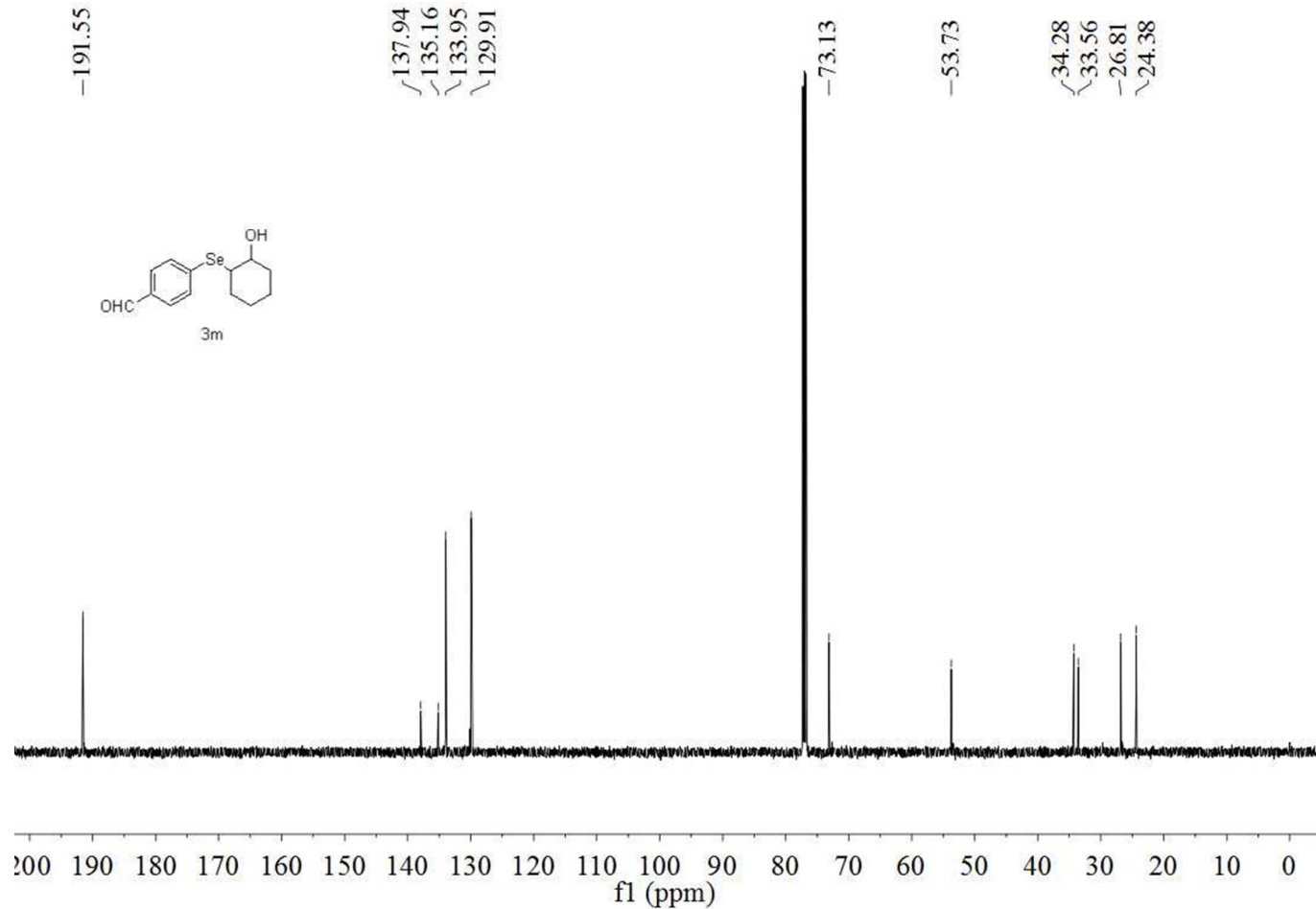


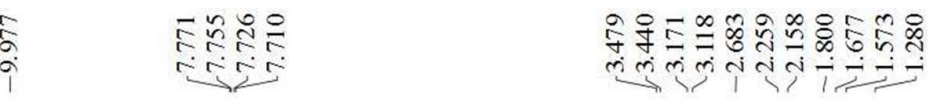
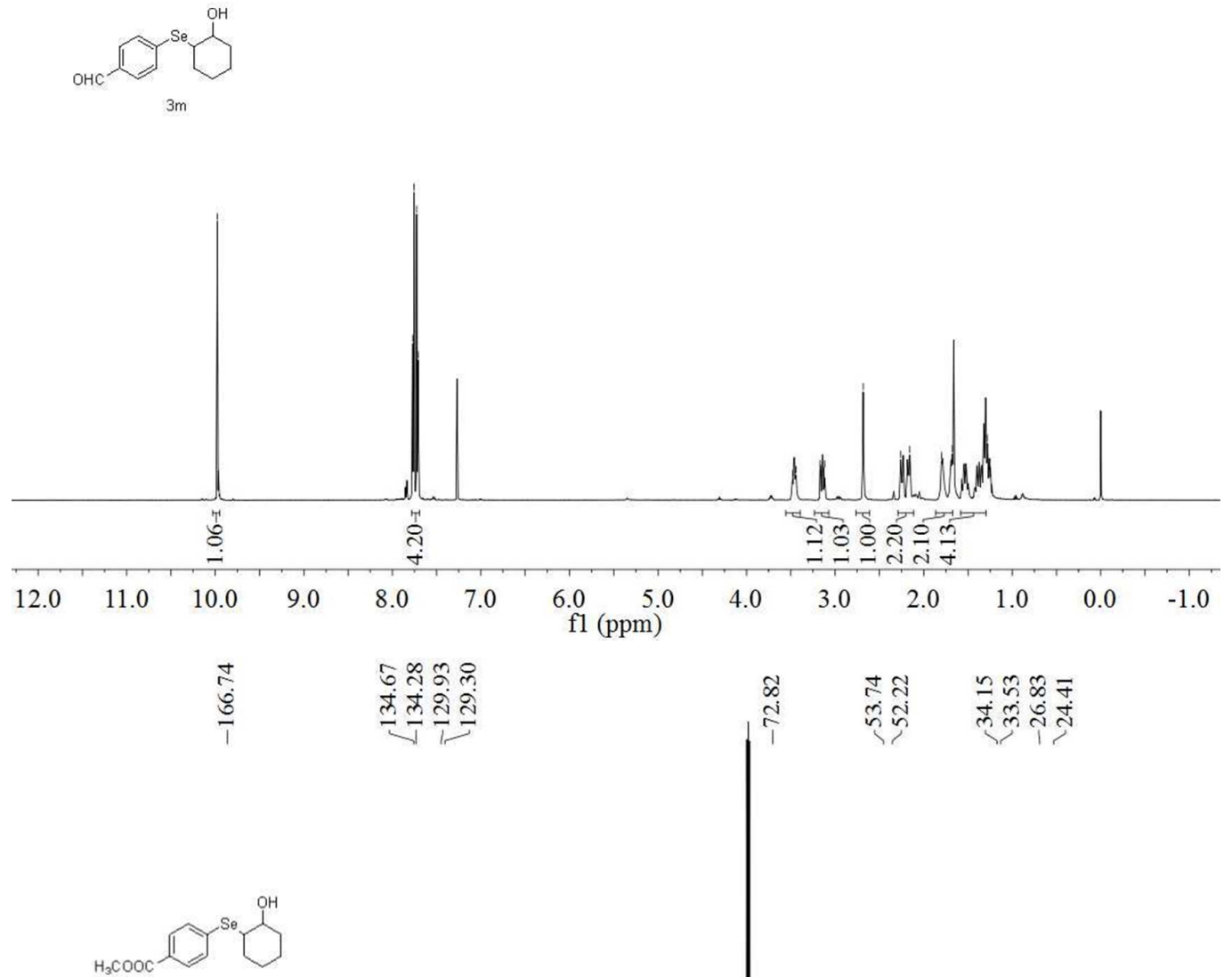

$3 n$

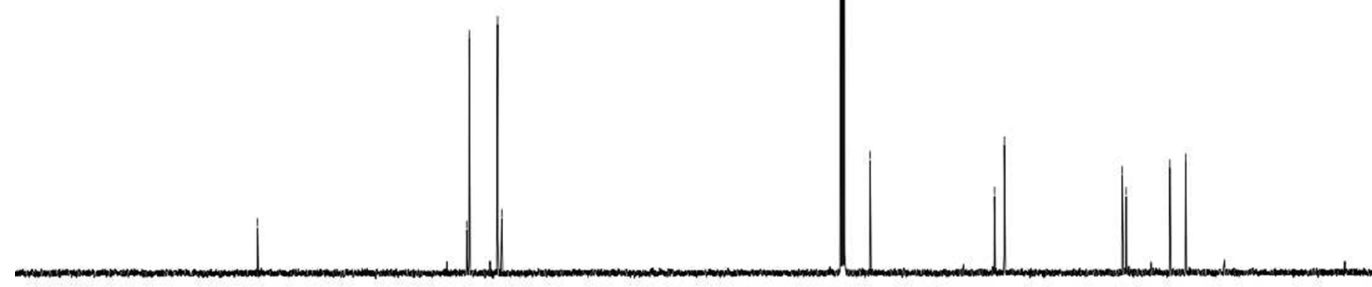

200

$\begin{array}{lllllllllll}190 & 180 & 170 & 160 & 150 & 140 & 130 & 120 & 110 & 100 & 90\end{array}$

$\begin{array}{lllllllll}80 & 70 & 60 & 50 & 40 & 30 & 20 & 10 & 0\end{array}$ f1 (ppm) 


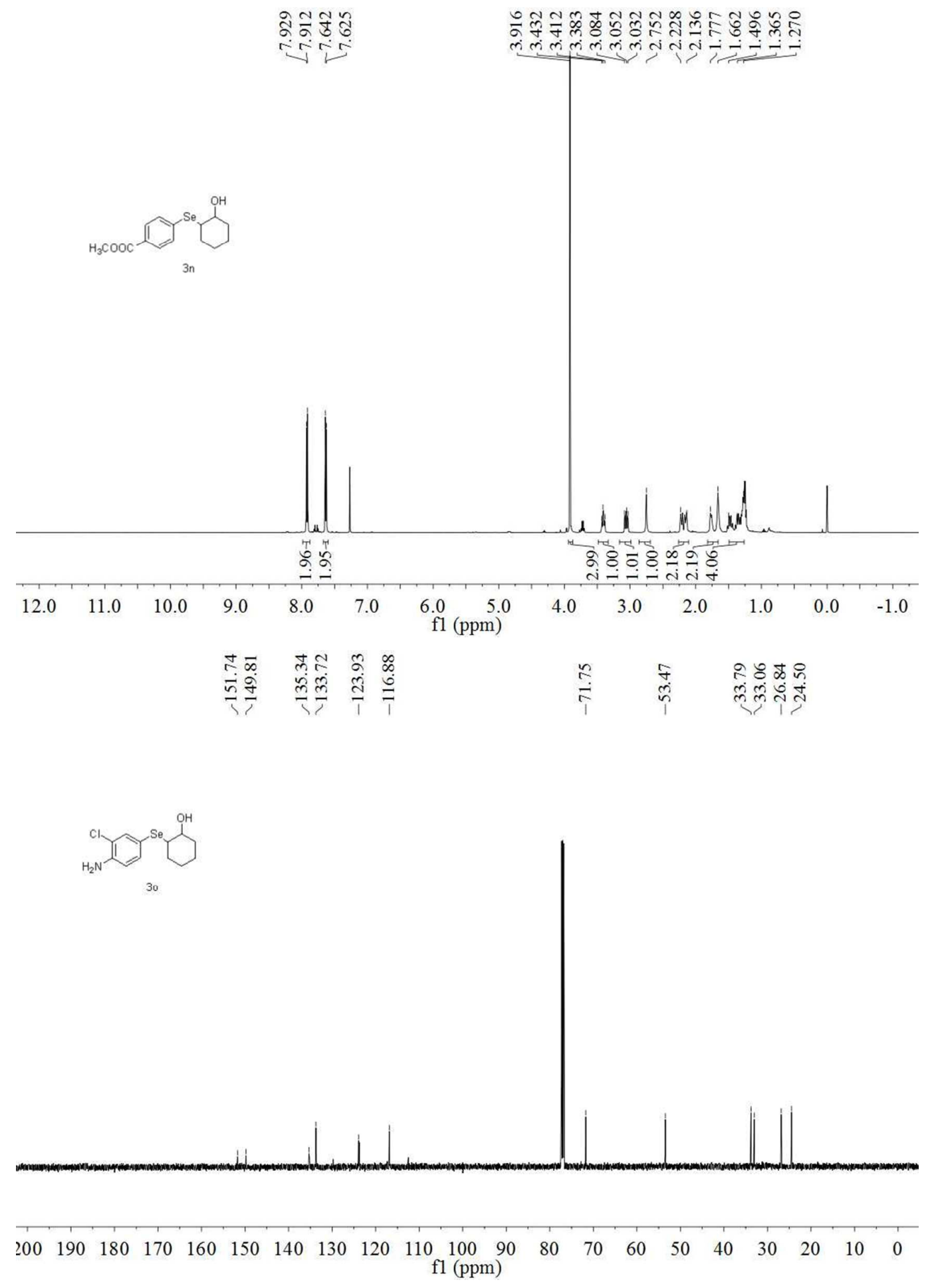




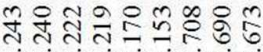 \\ $\sin 2 \pi 000$

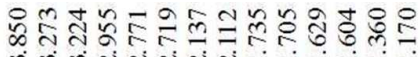

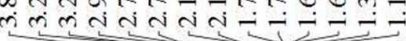

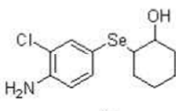

30

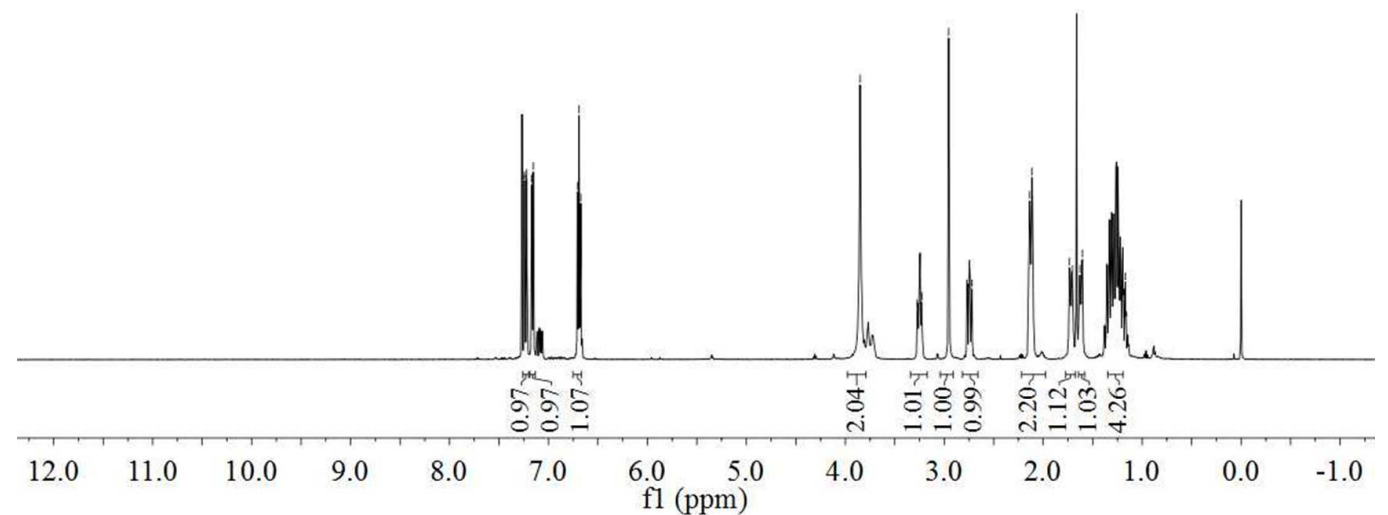

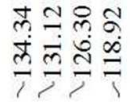

$\infty \quad \& \Leftrightarrow \& \&$

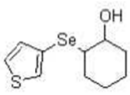

$3 p$

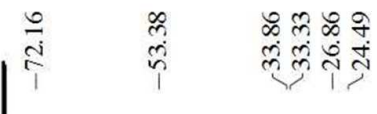

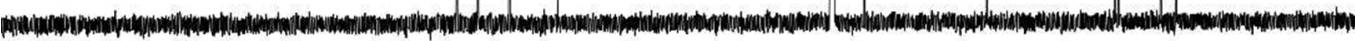

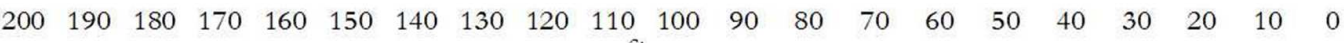

f1 (ppm) 


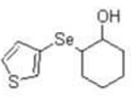

$3 p$

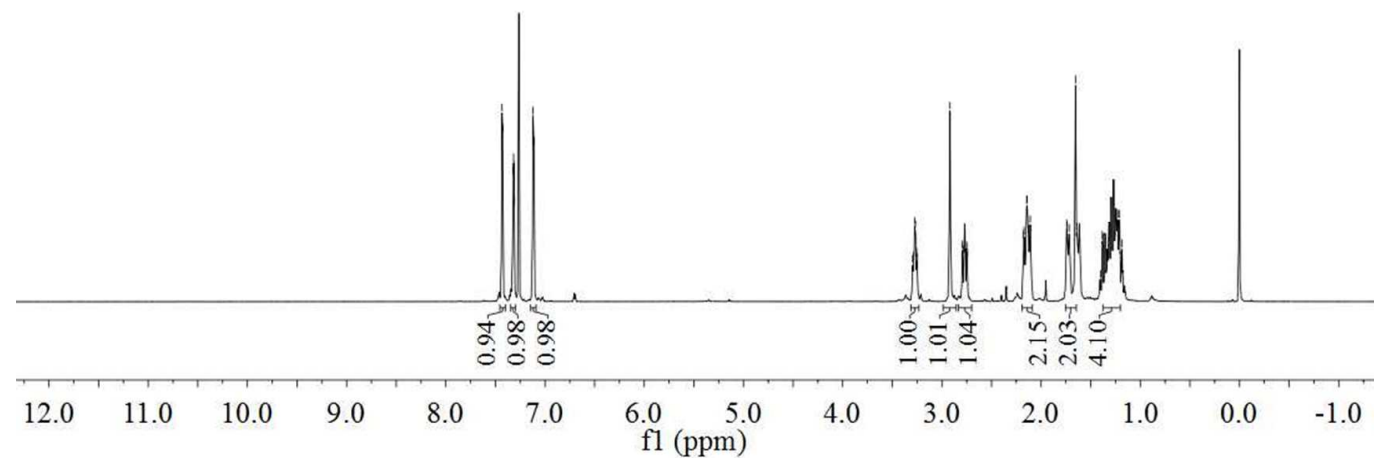

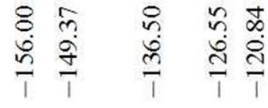

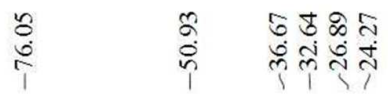

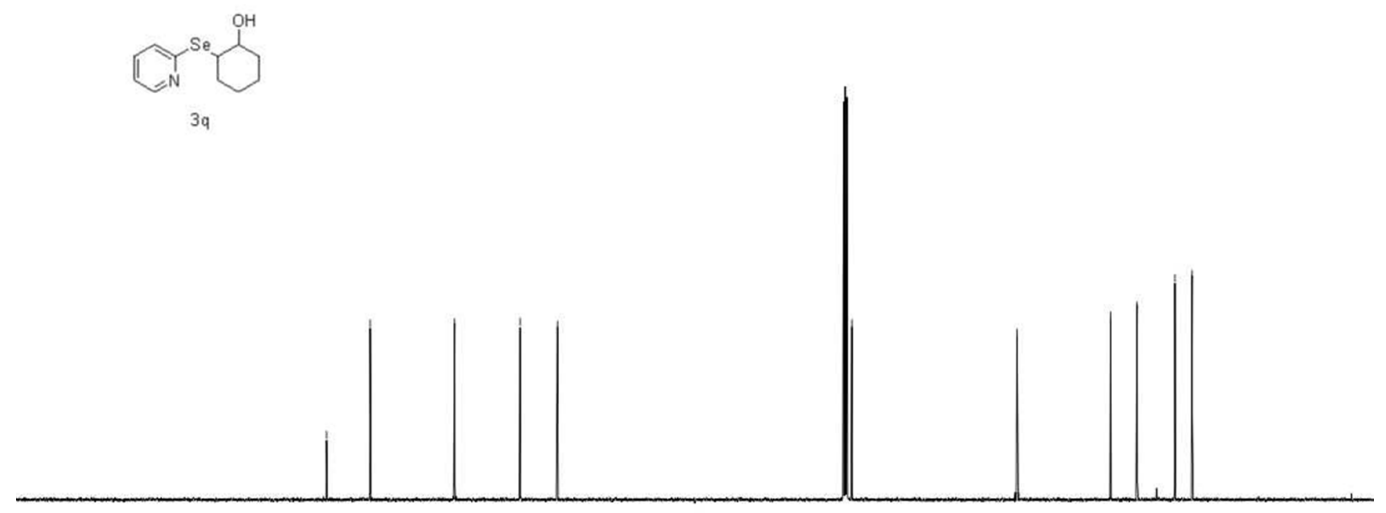

$\begin{array}{llllllllllllllllllll}200 & 190 & 180 & 170 & 160 & 150 & 140 & 130 & 120 & 110 \underset{\mathrm{f} 1}{100}(\mathrm{ppm}) & 90 & 80 & 70 & 60 & 50 & 40 & 30 & 20 & 10 & 0\end{array}$ 

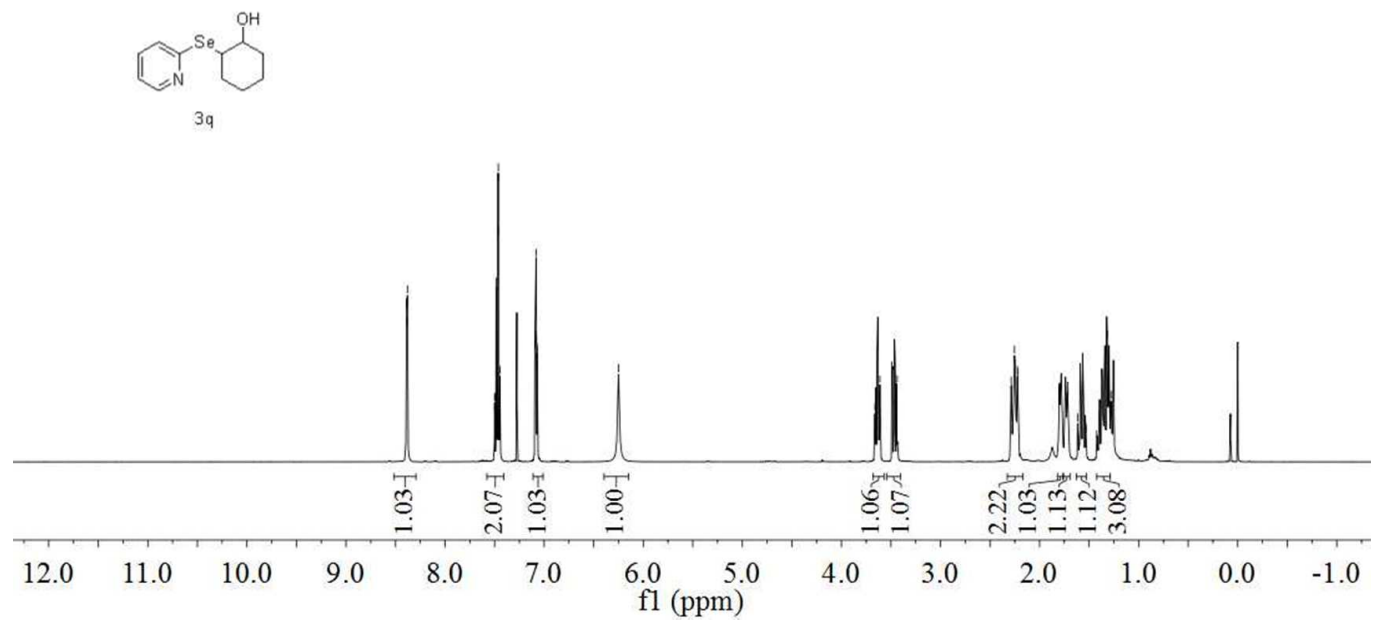

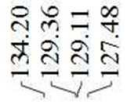

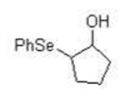

$4 a$

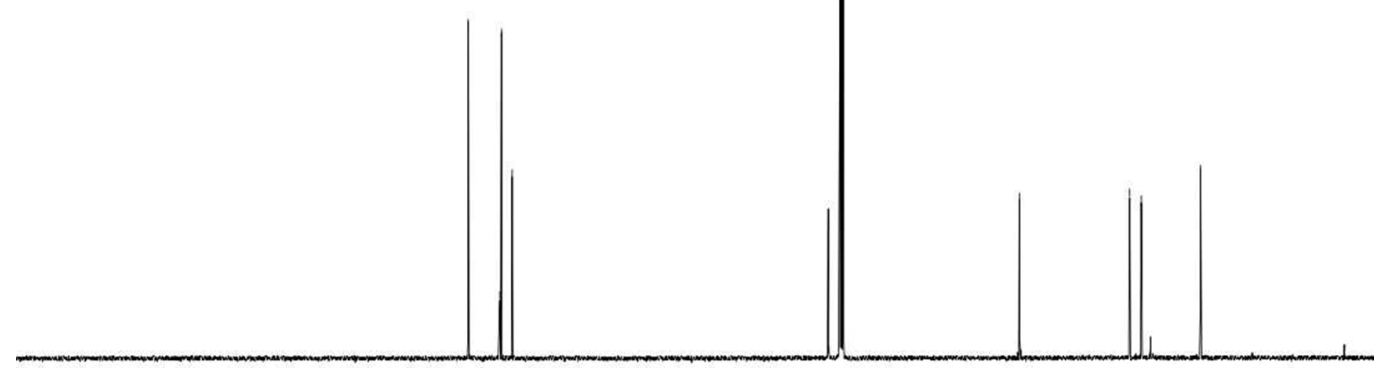

$\begin{array}{lllllllllllllllllllll}200 & 190 & 180 & 170 & 160 & 150 & 140 & 130 & 120 & 110 & 100 & 90 & 80 & 70 & 60 & 50 & 40 & 30 & 20 & 10 & 0\end{array}$ f1 (ppm) 

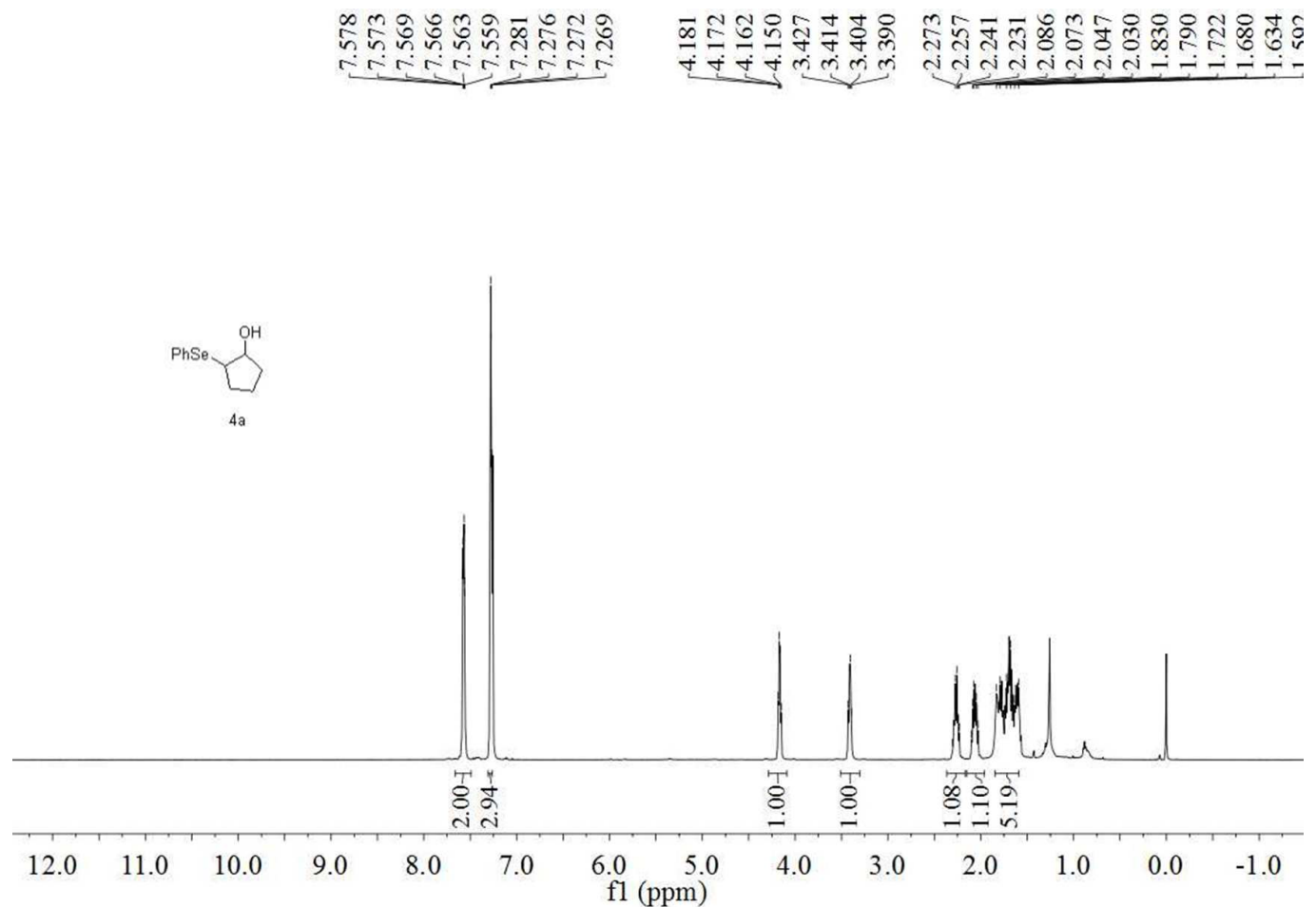

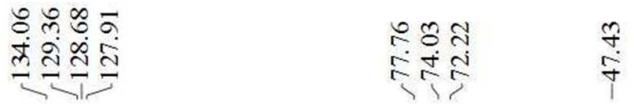

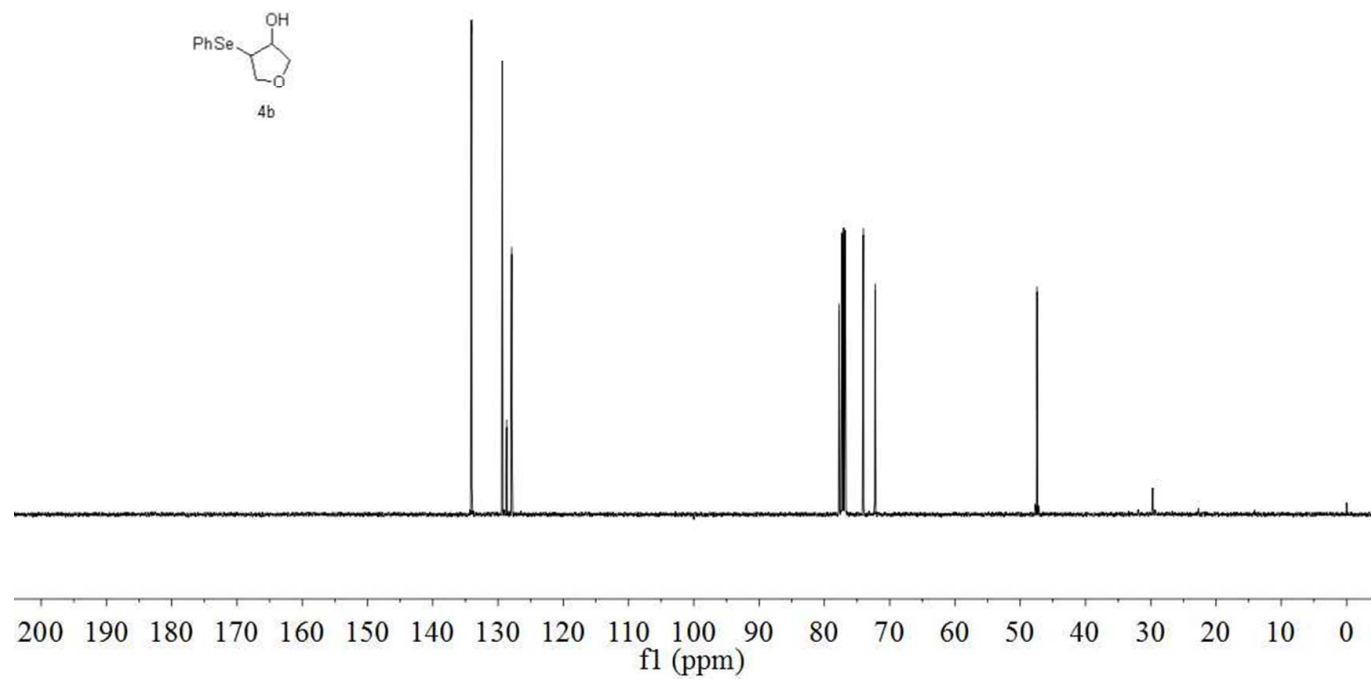



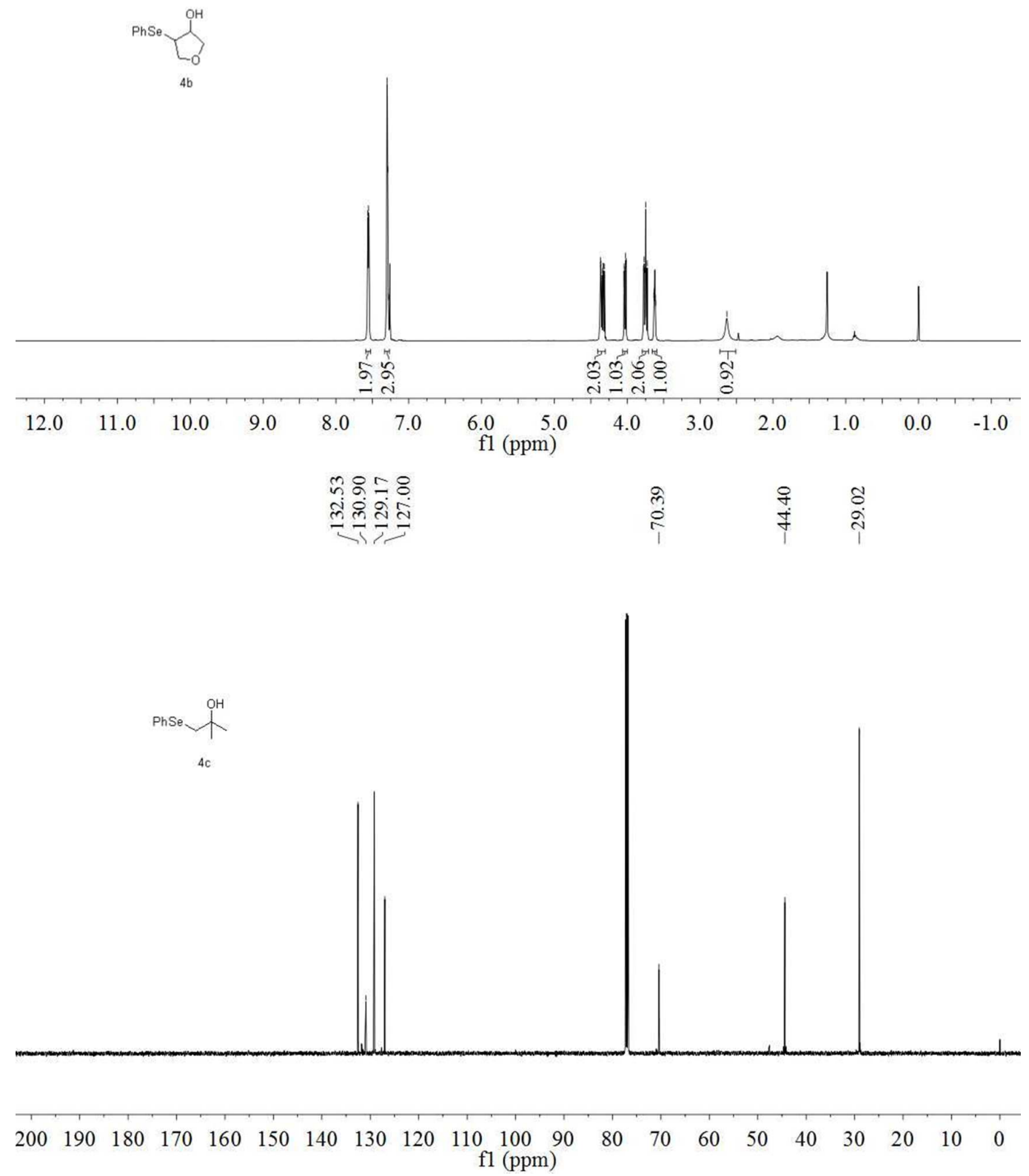


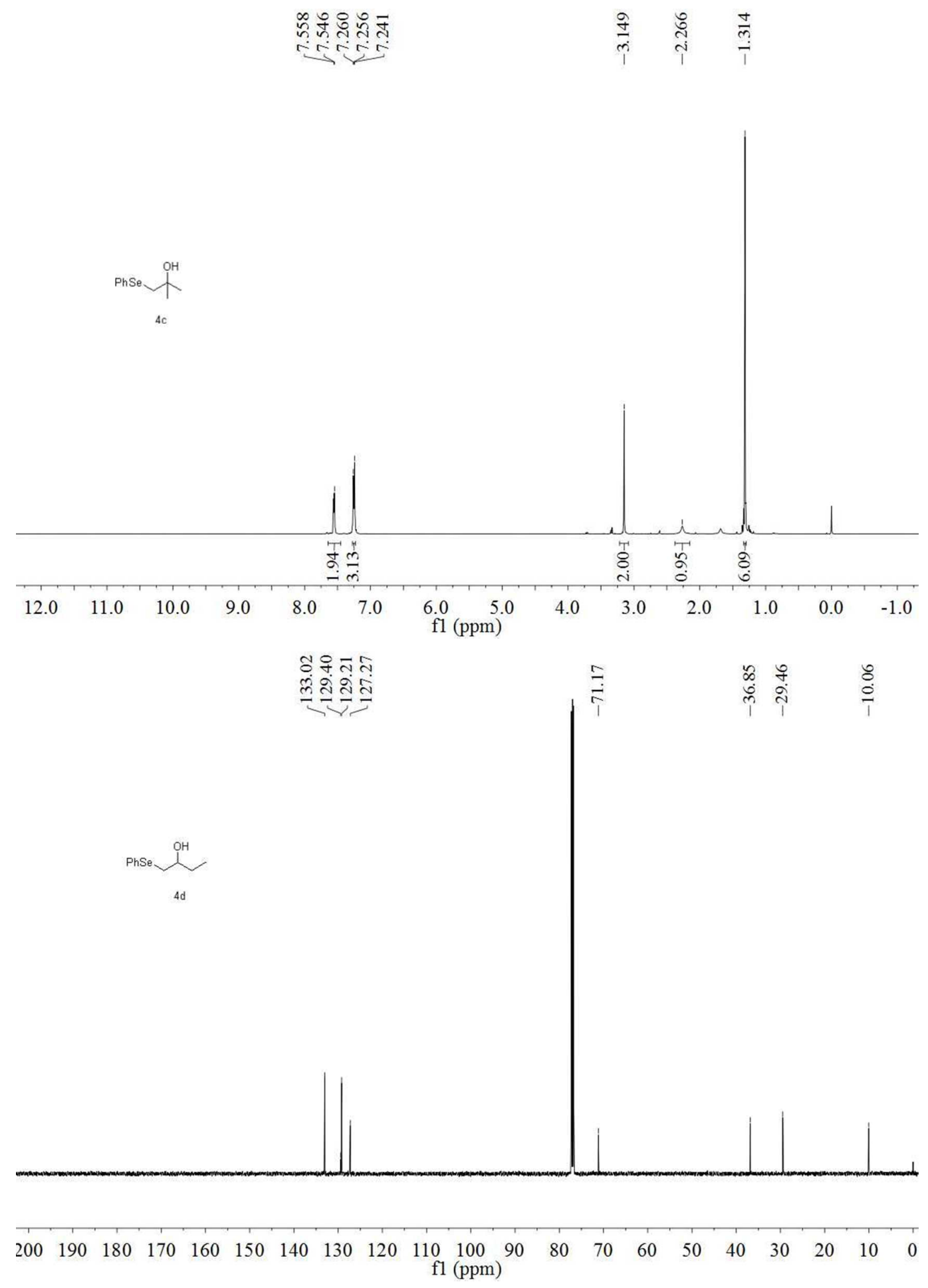




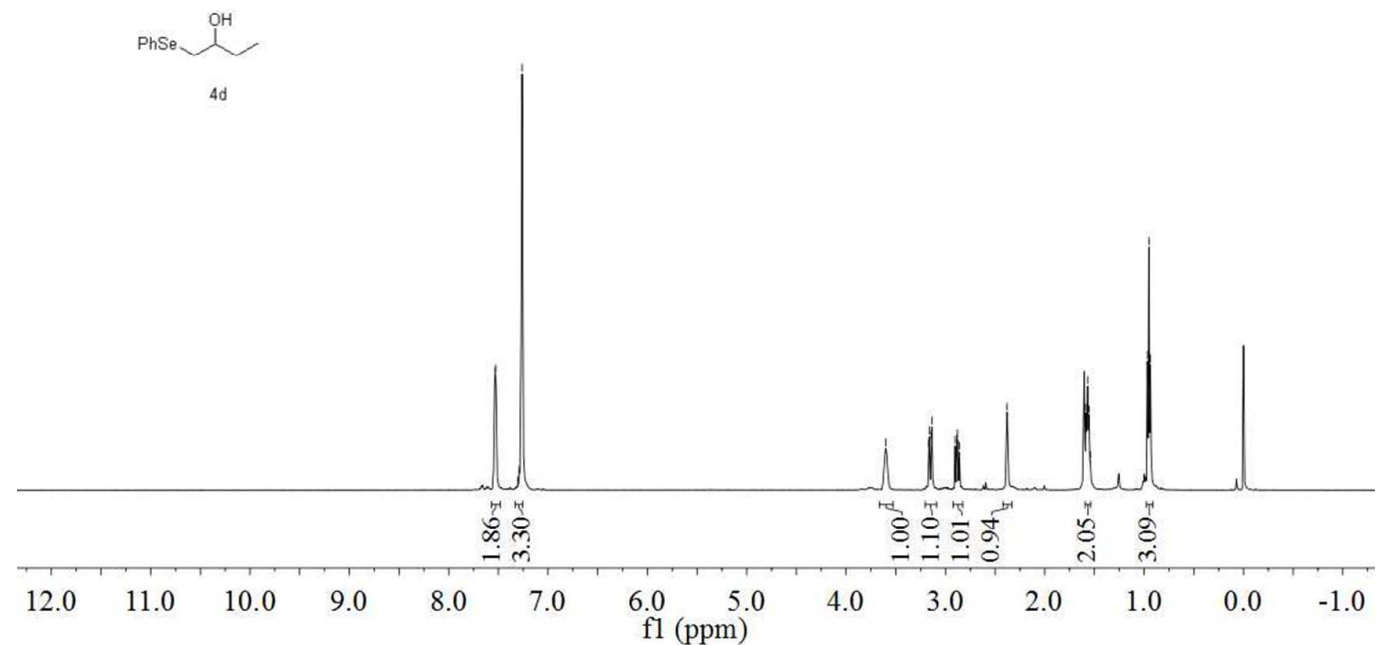

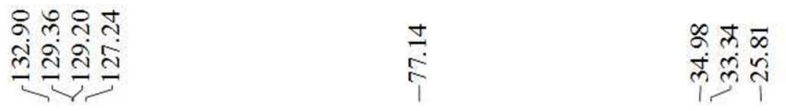

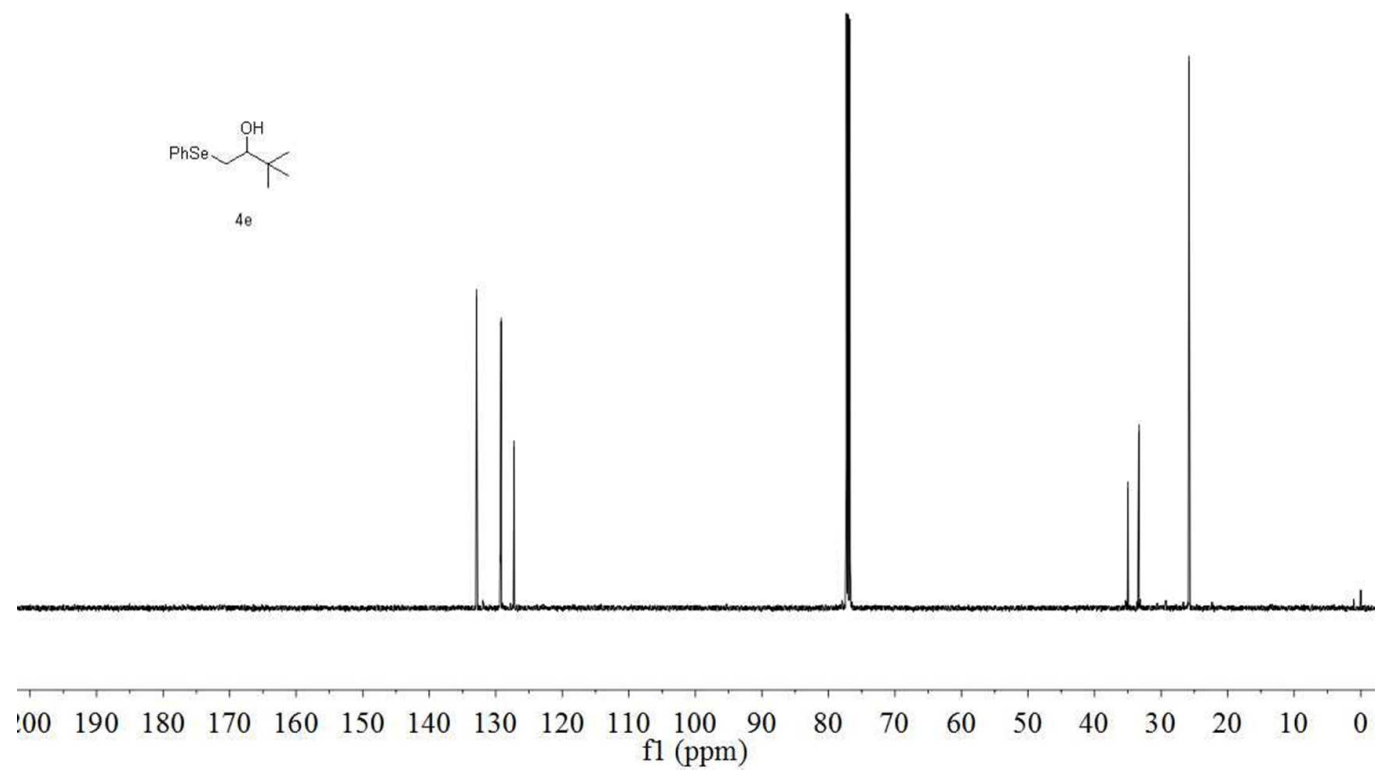




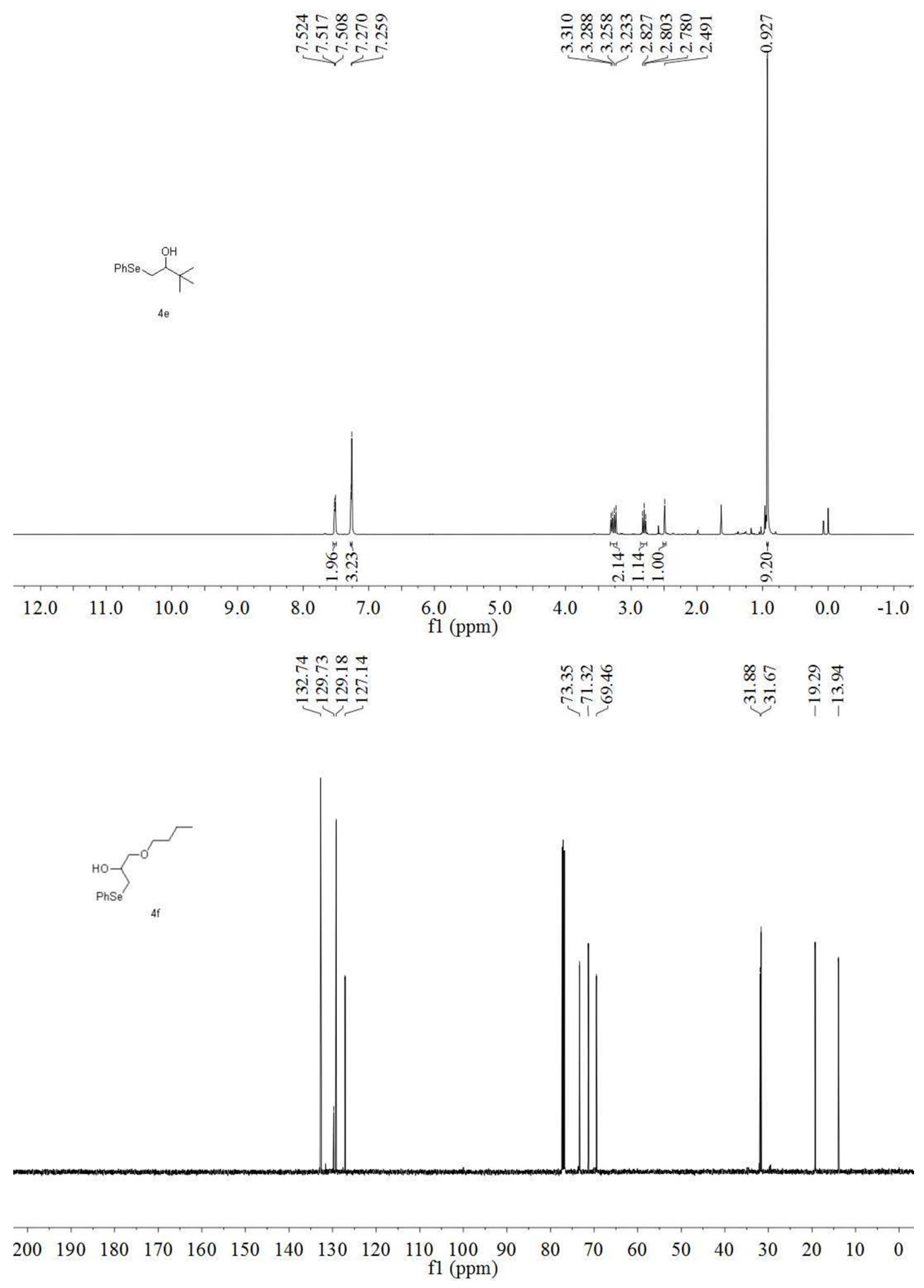




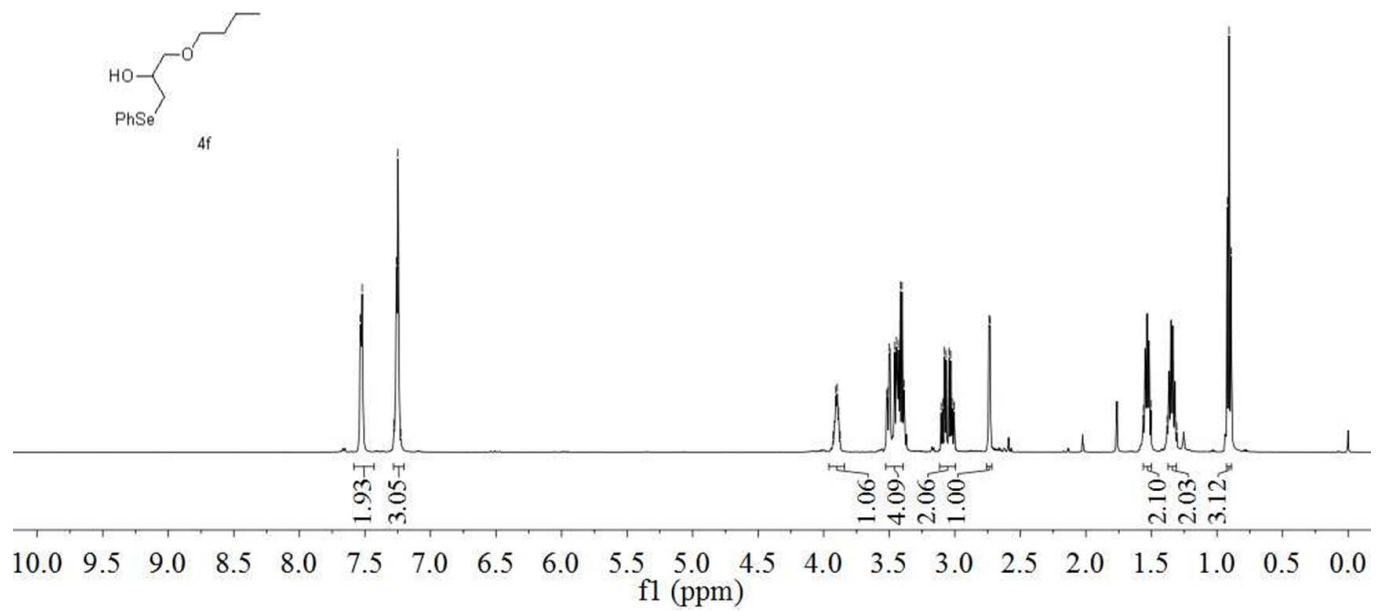

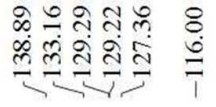
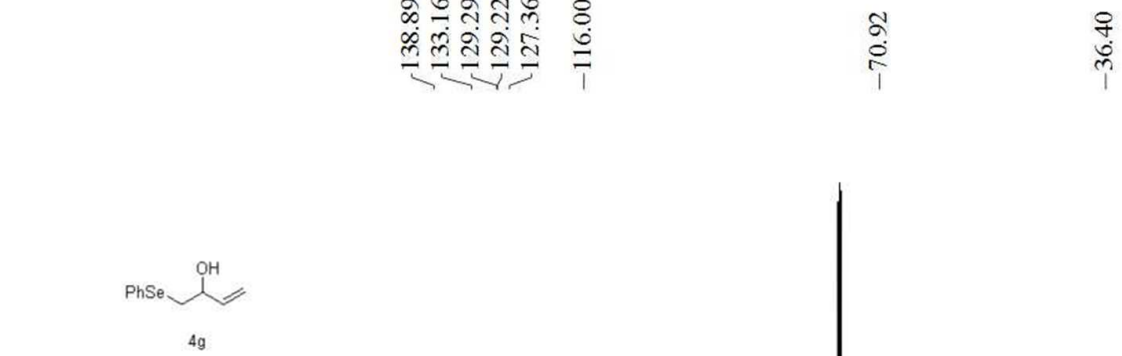

49

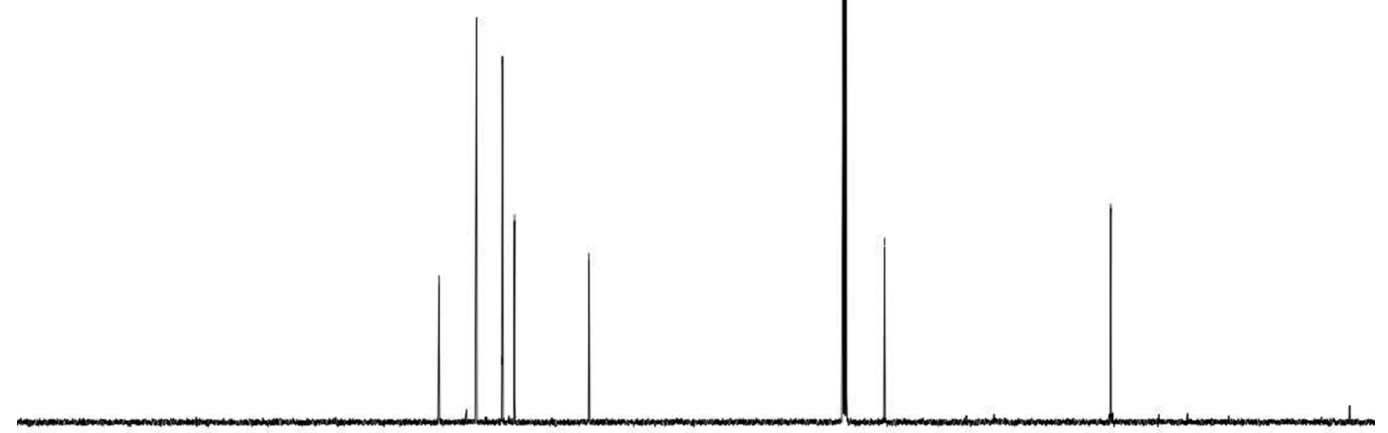

$\begin{array}{lllllllllllllllllllll}200 & 190 & 180 & 170 & 160 & 150 & 140 & 130 & 120 & 110 & 100 & 90 & 80 & 70 & 60 & 50 & 40 & 30 & 20 & 10 & 0\end{array}$ f1 (ppm) 

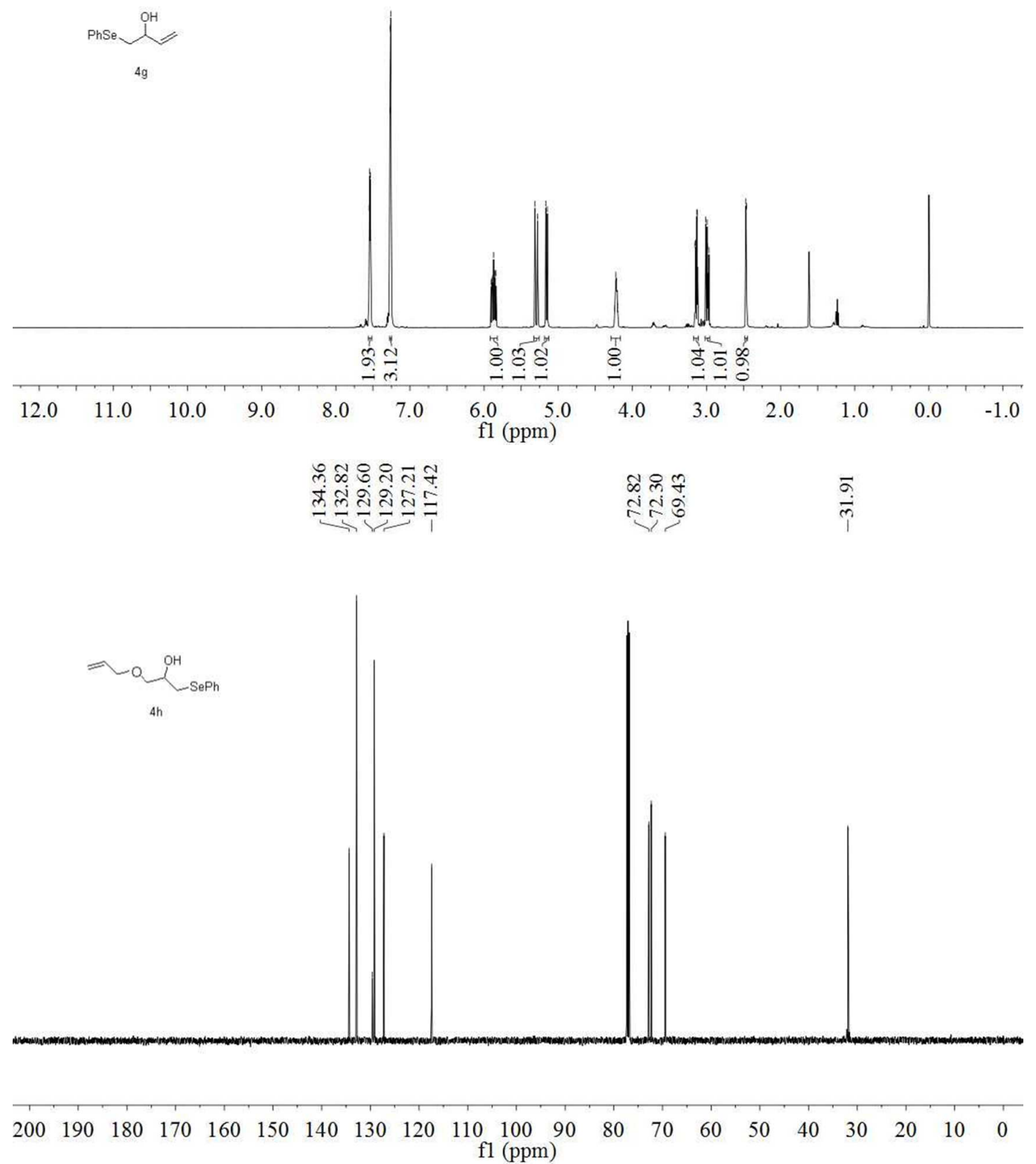


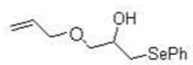

$4 h$
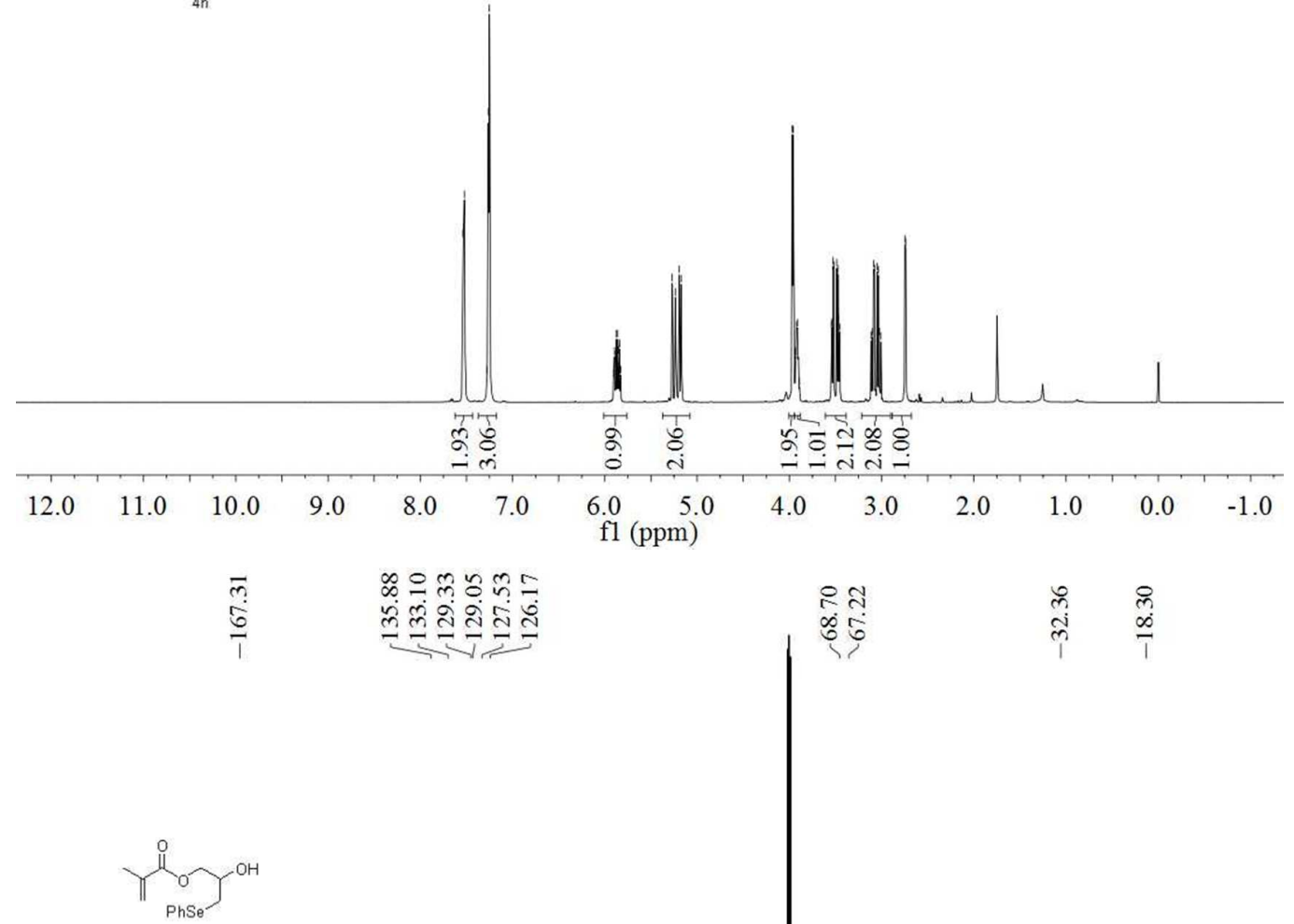

$4 i$

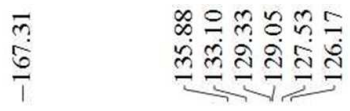

क⿺辶一兀

$\begin{array}{ll}\text { m } & \text { m } \\ \text { m } & \text { । }\end{array}$

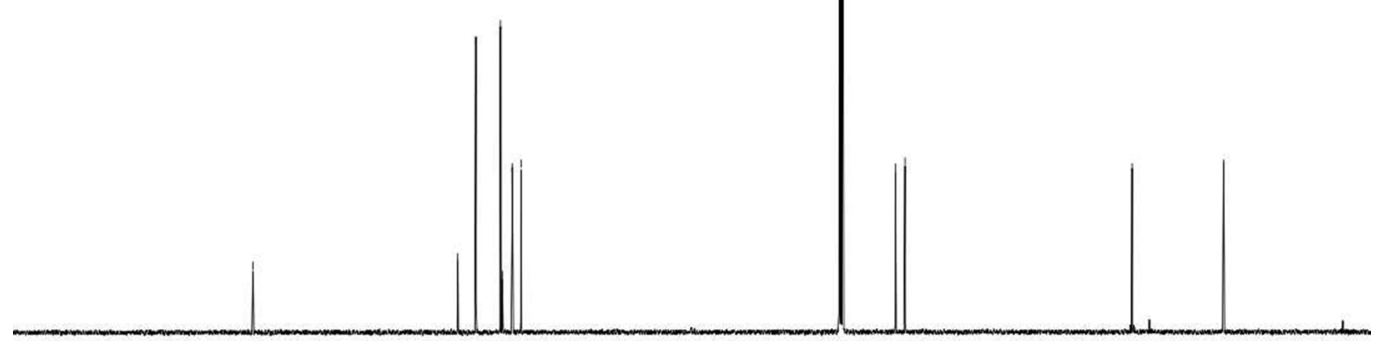

2001

$90 \quad 180$

$70 \quad 160150$

$\begin{array}{lll}50 & 140\end{array}$

$120 \quad 110$

f1 (ppm)

$\begin{array}{lllllllll}80 & 70 & 60 & 50 & 40 & 30 & 20 & 10 & 0\end{array}$

(ppm) 

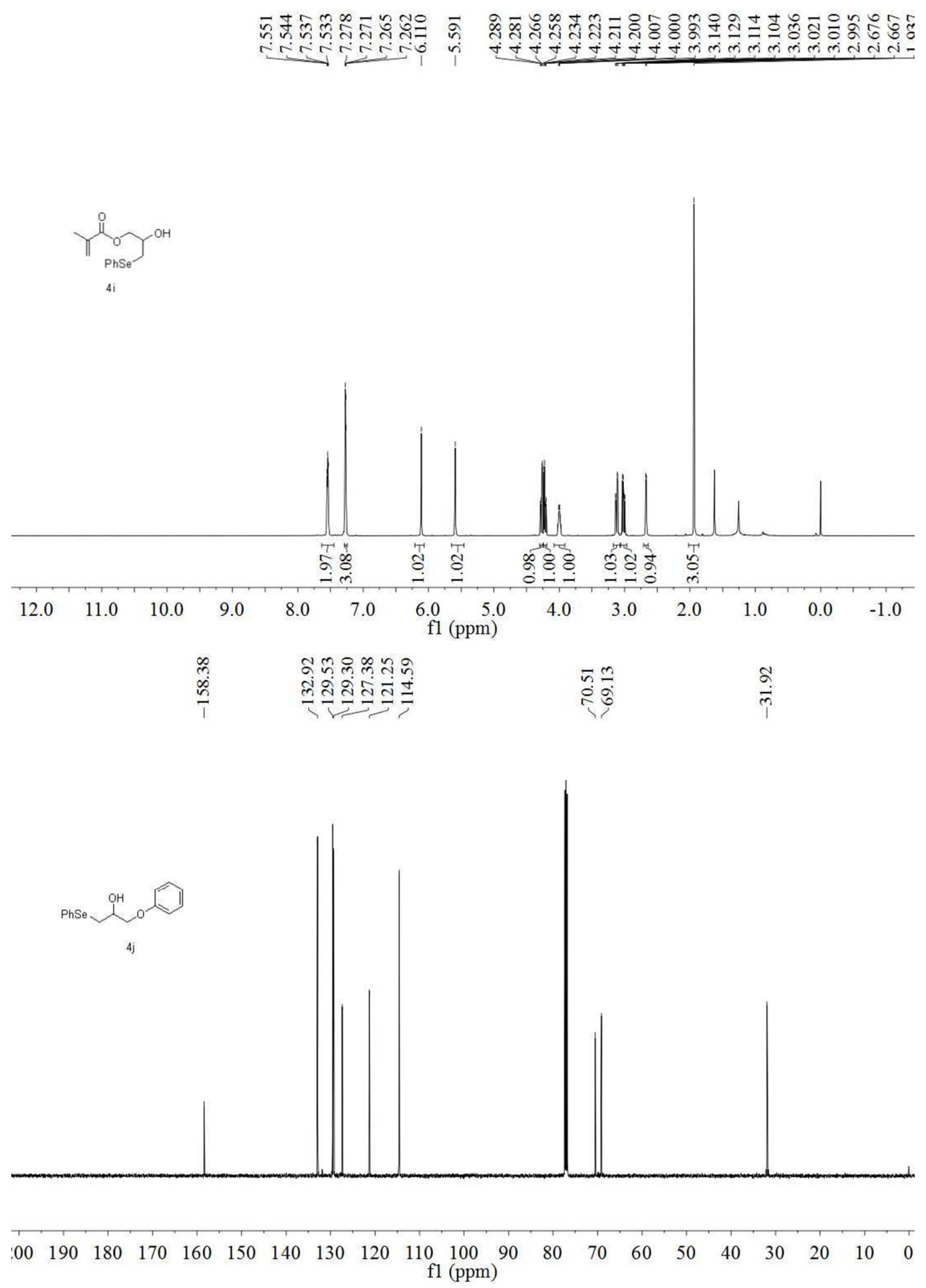

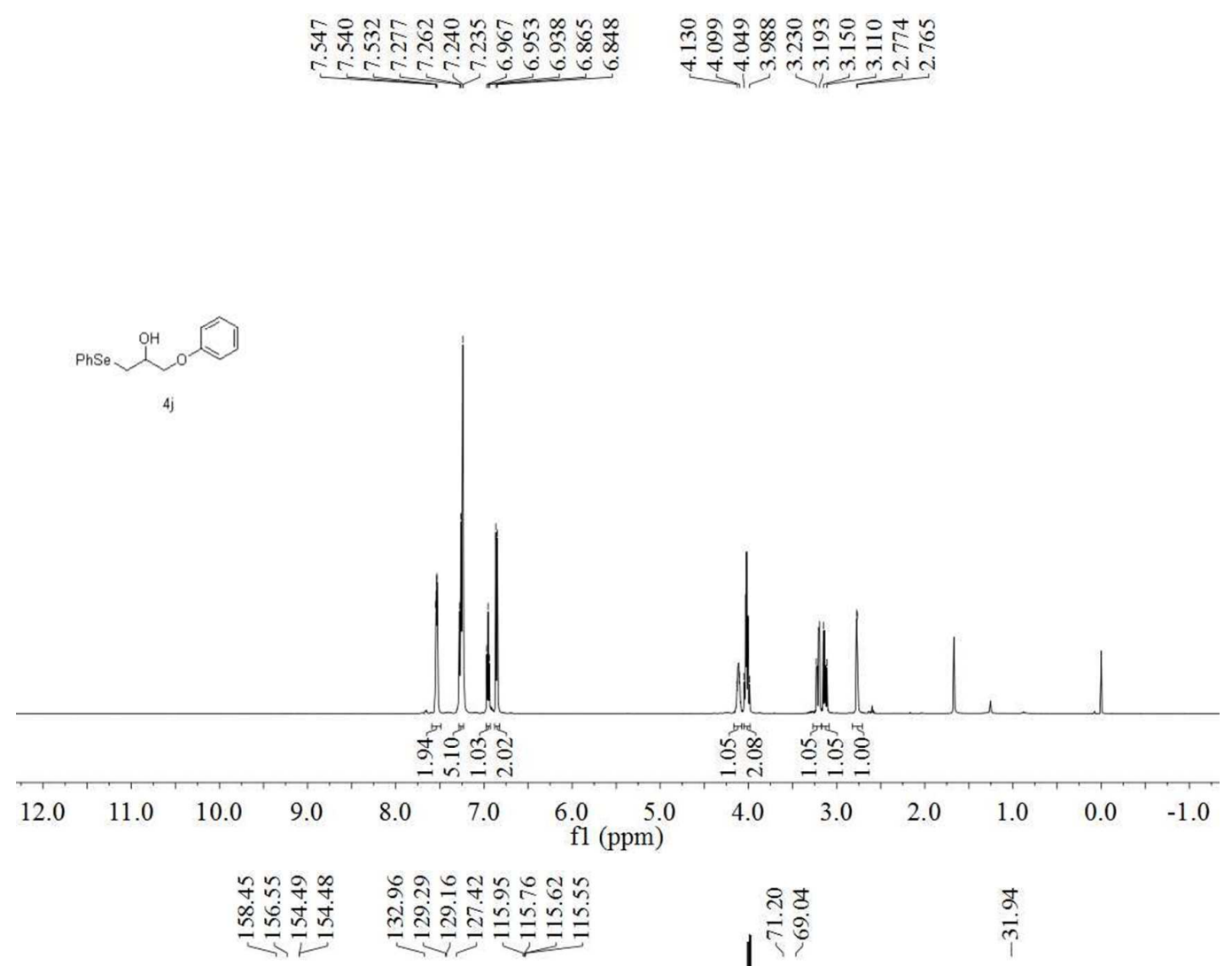

n

每落

(
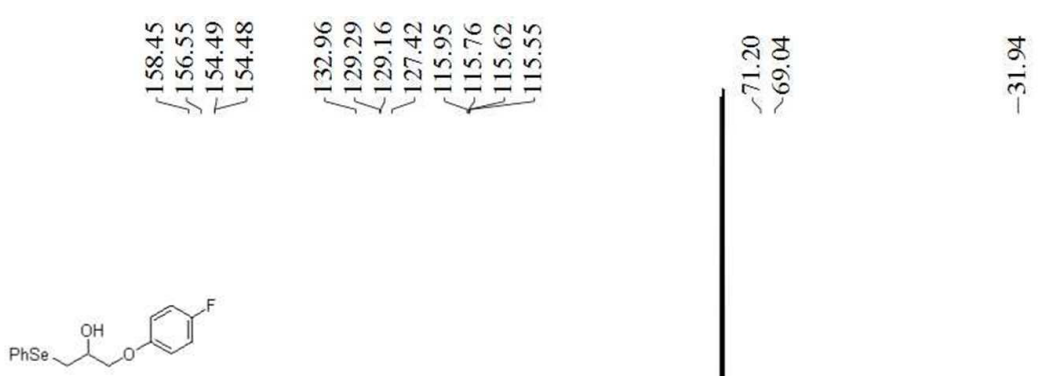

$4 k$
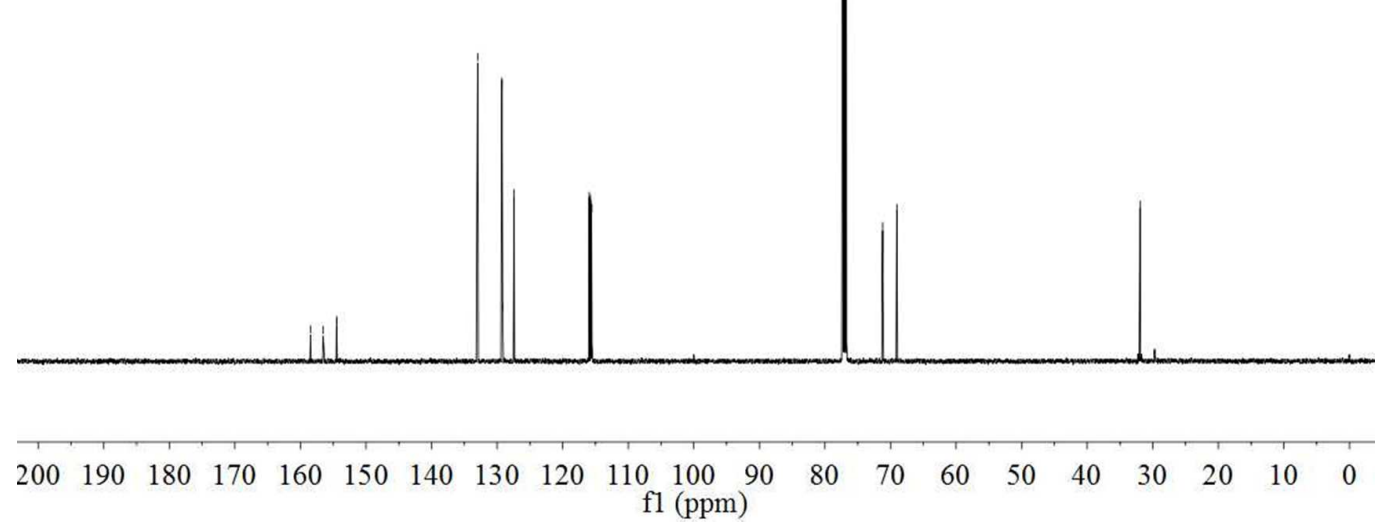


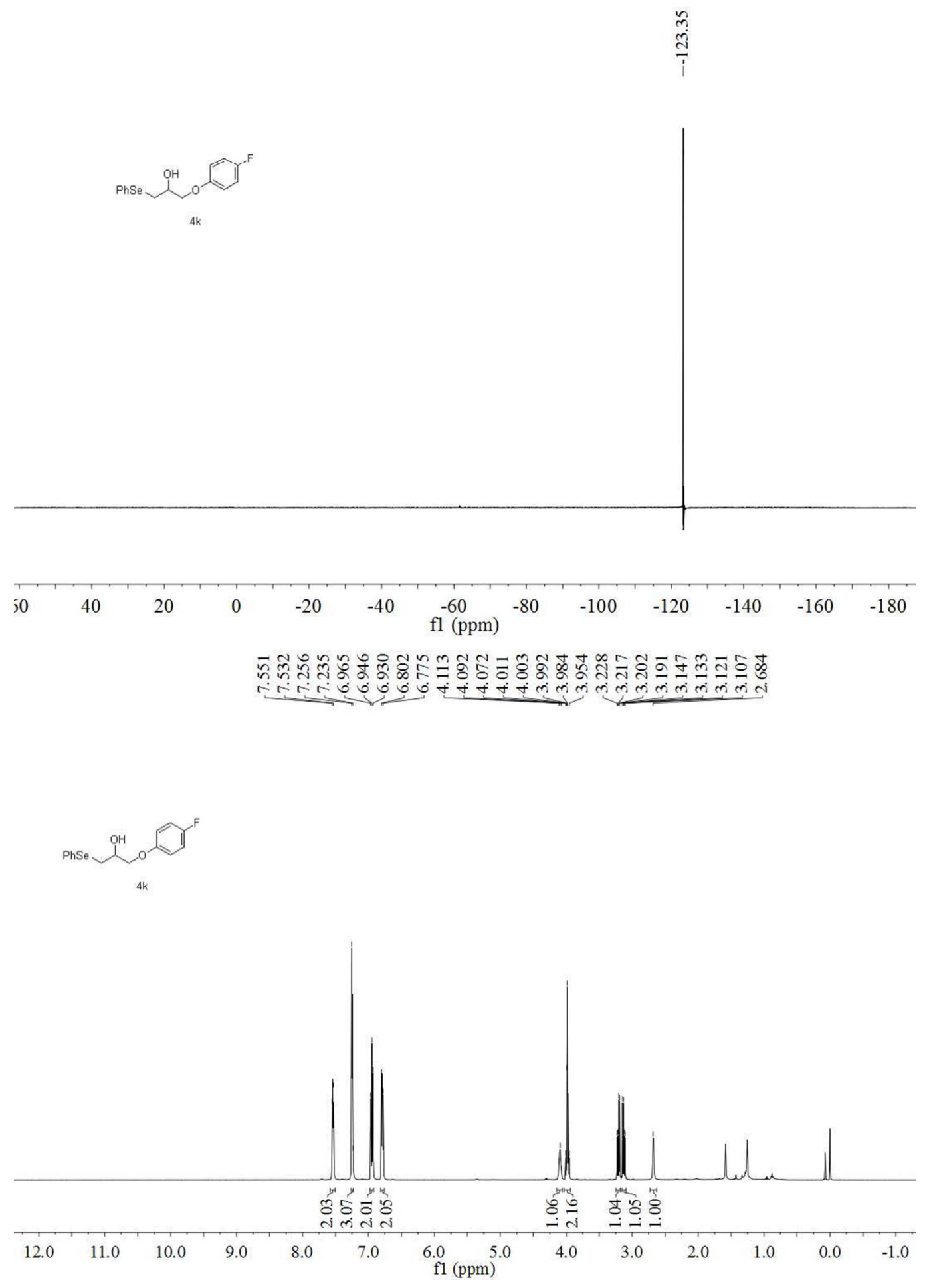




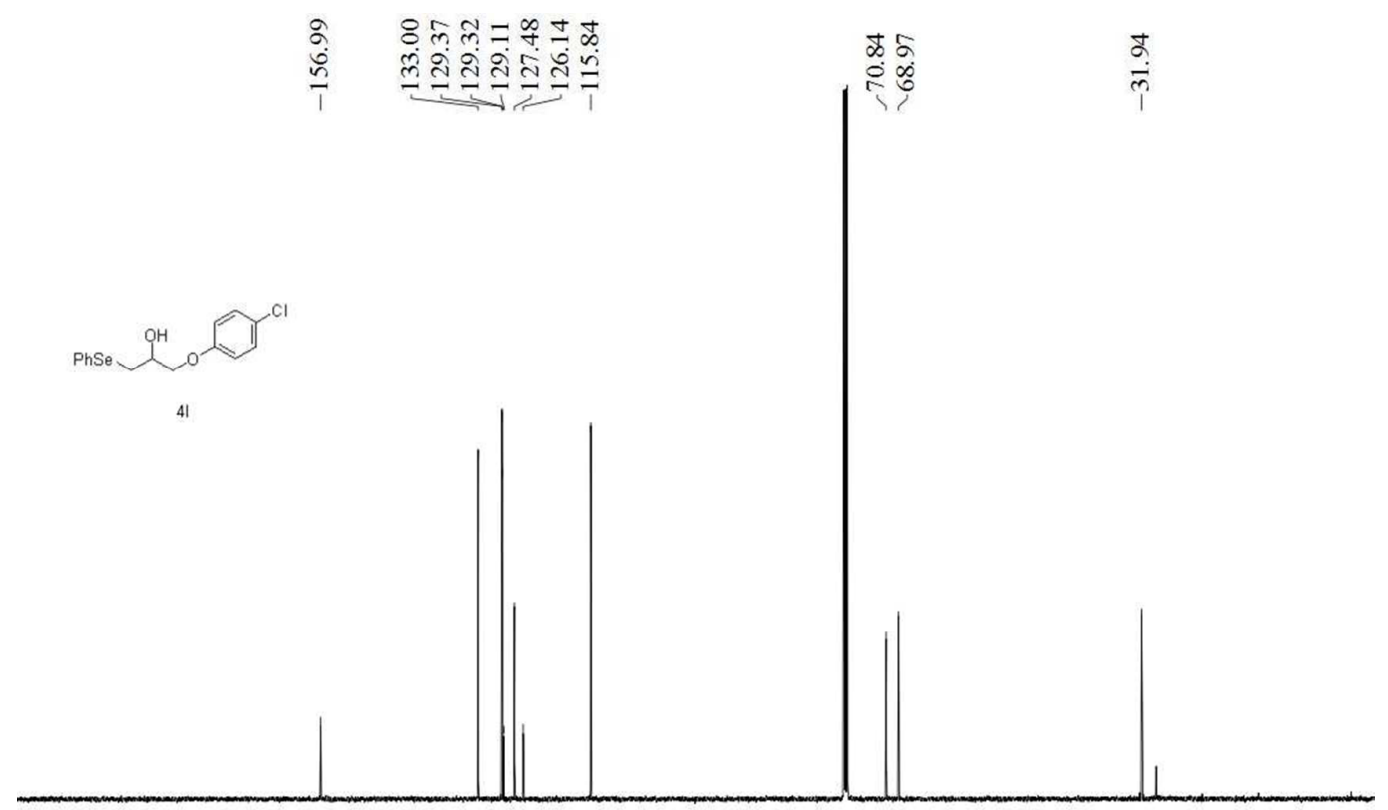

$\begin{array}{llllllllllllllllllll}200 & 190 & 180 & 170 & 160 & 150 & 140 & 130 & 120 & 110 \begin{array}{c}100 \\ \mathrm{f1}(\mathrm{ppm})\end{array} & 90 & 80 & 70 & 60 & 50 & 40 & 30 & 20 & 10 & 0\end{array}$

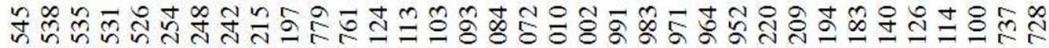

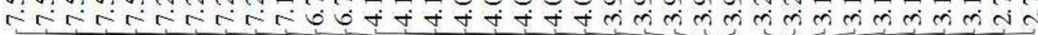

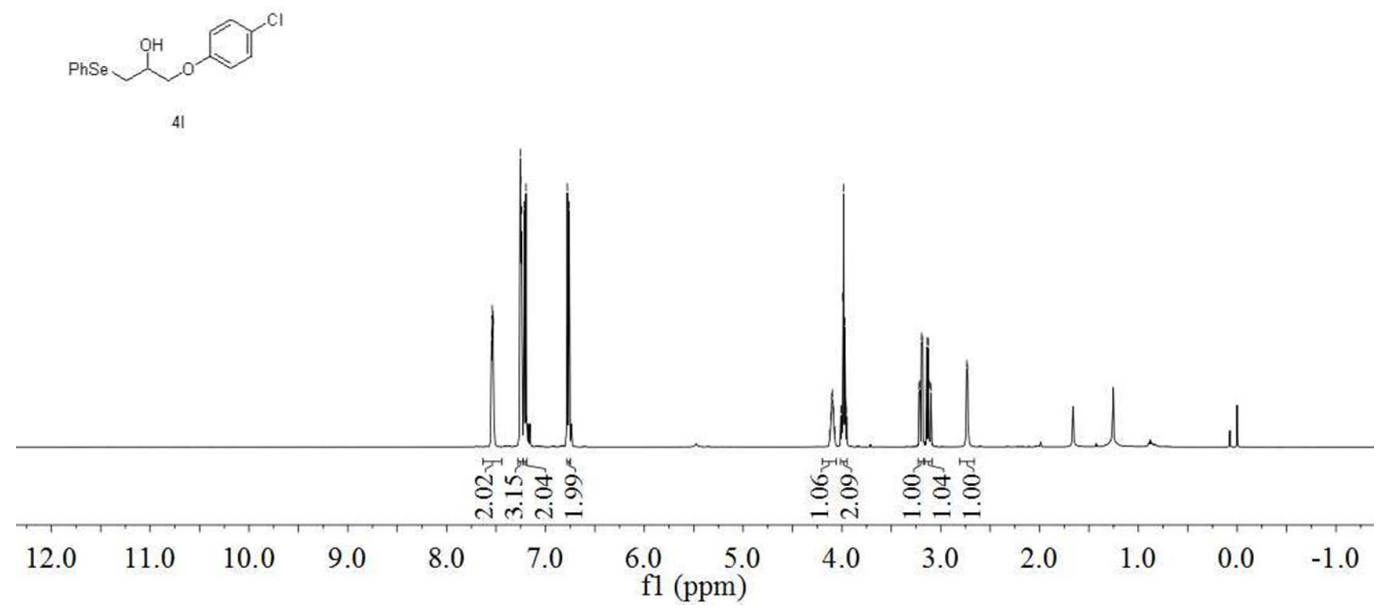



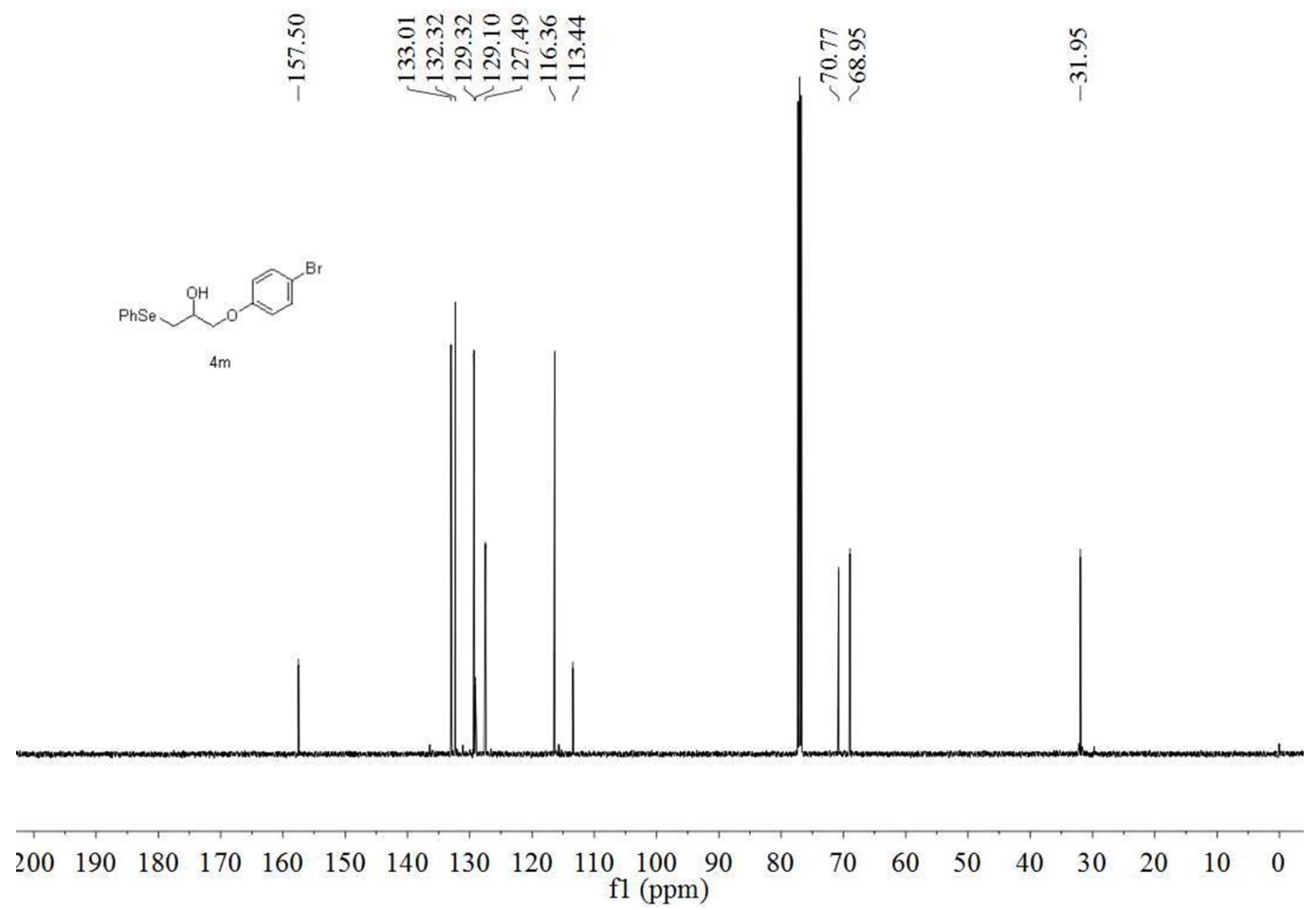

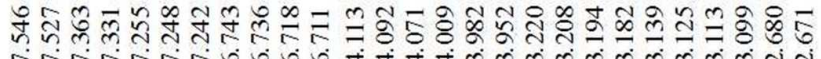

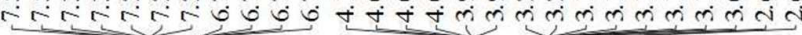

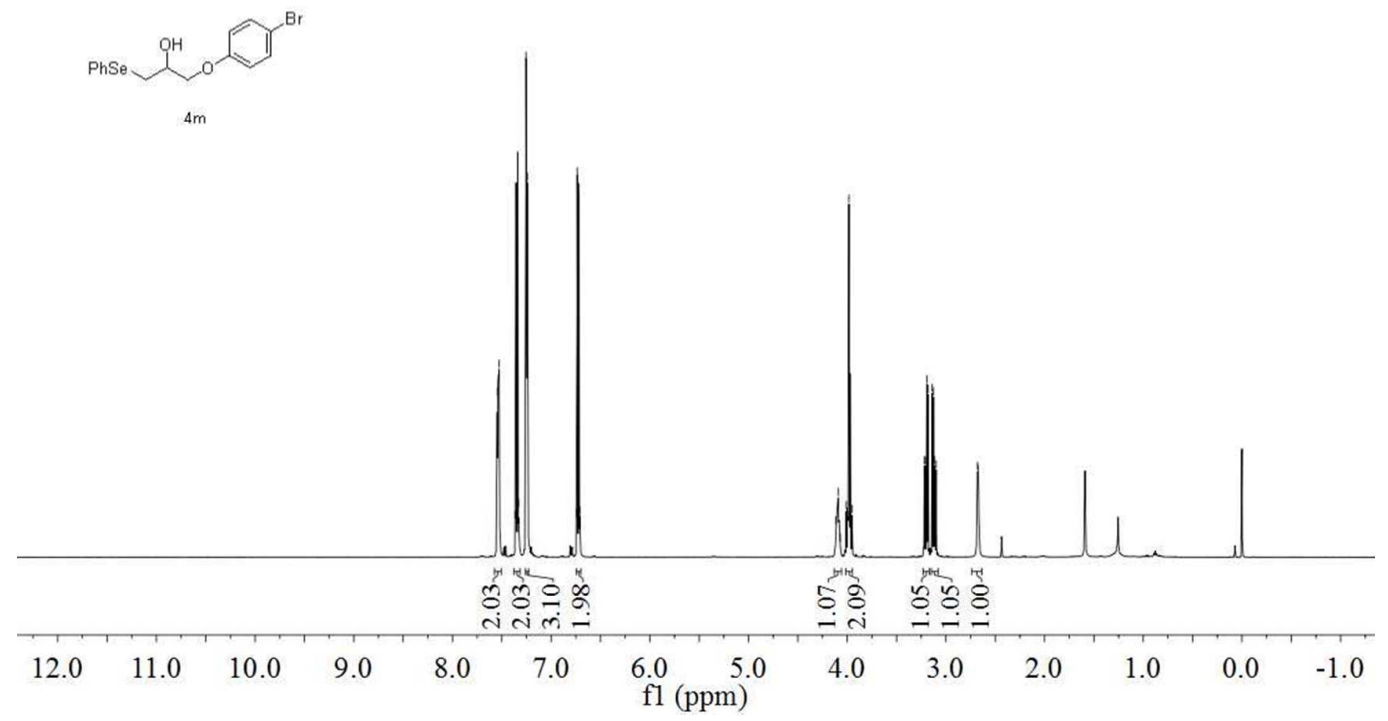




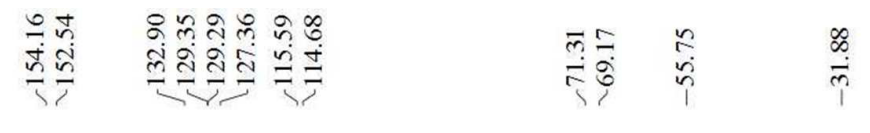
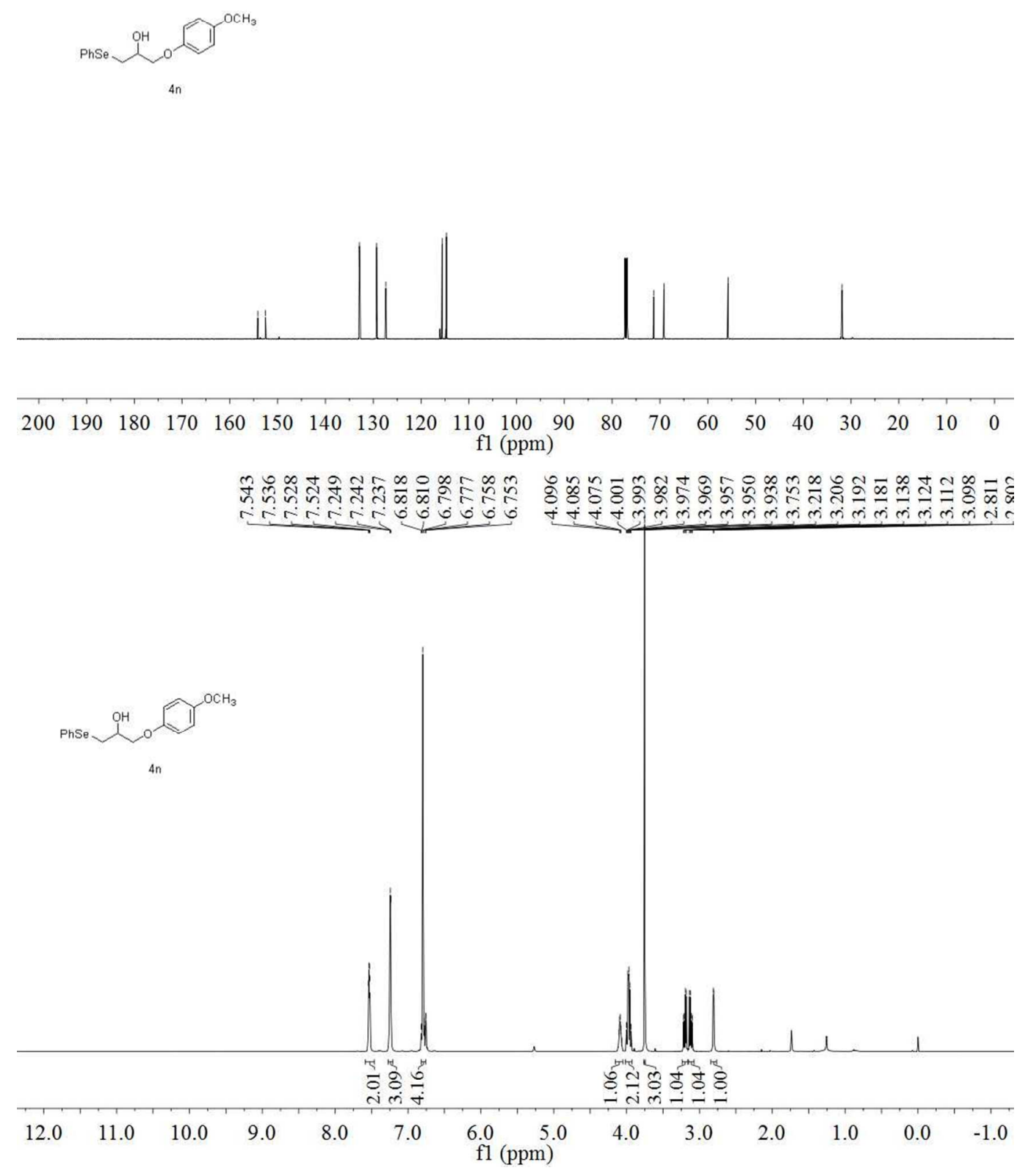


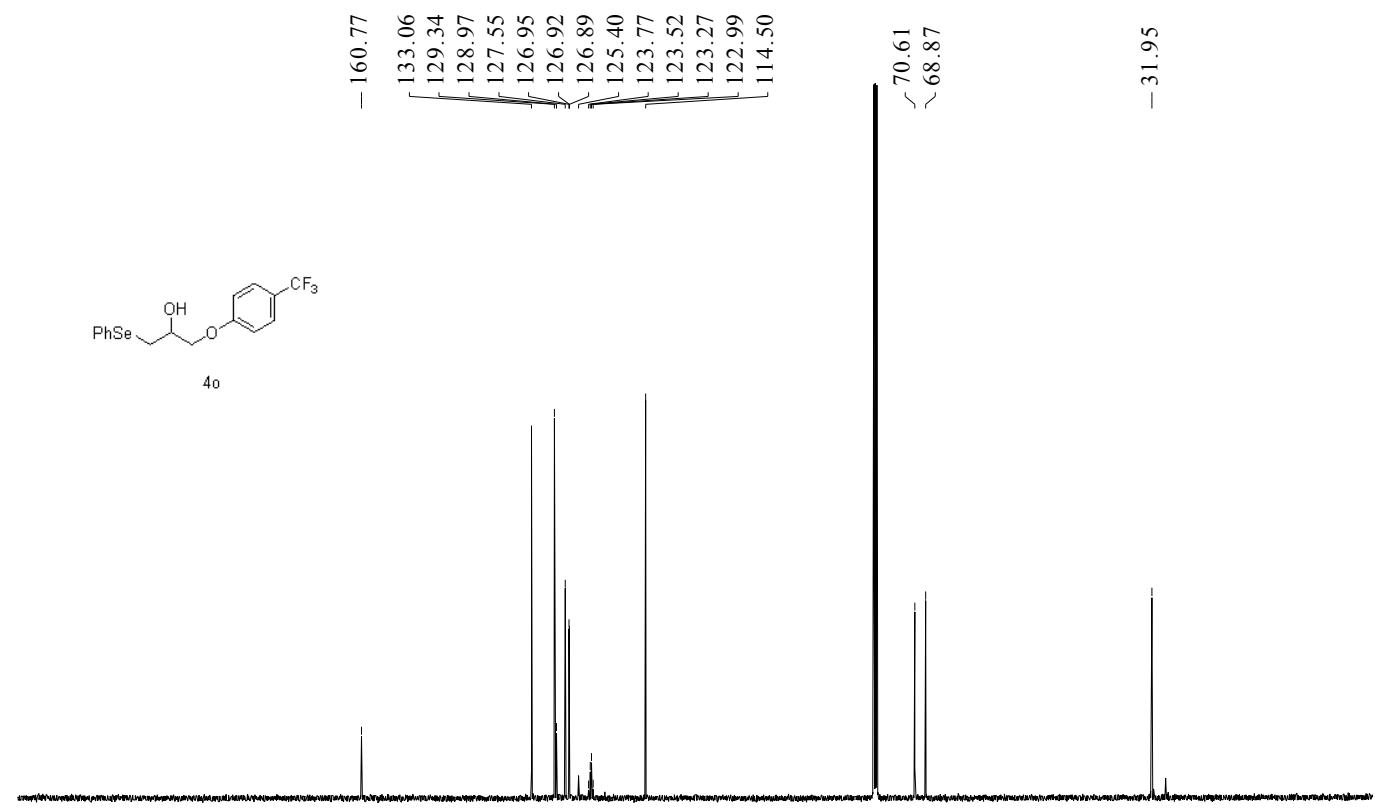

$\begin{array}{llllllllllllllllllllll}210 & 200 & 190 & 180 & 170 & 160 & 150 & 140 & 130 & 120 & 110 & 100 & 90 & 80 & 70 & 60 & 50 & 40 & 30 & 20 & 10 & 0\end{array}$ f1 $(\mathrm{ppm})$

$\frac{n}{i}$

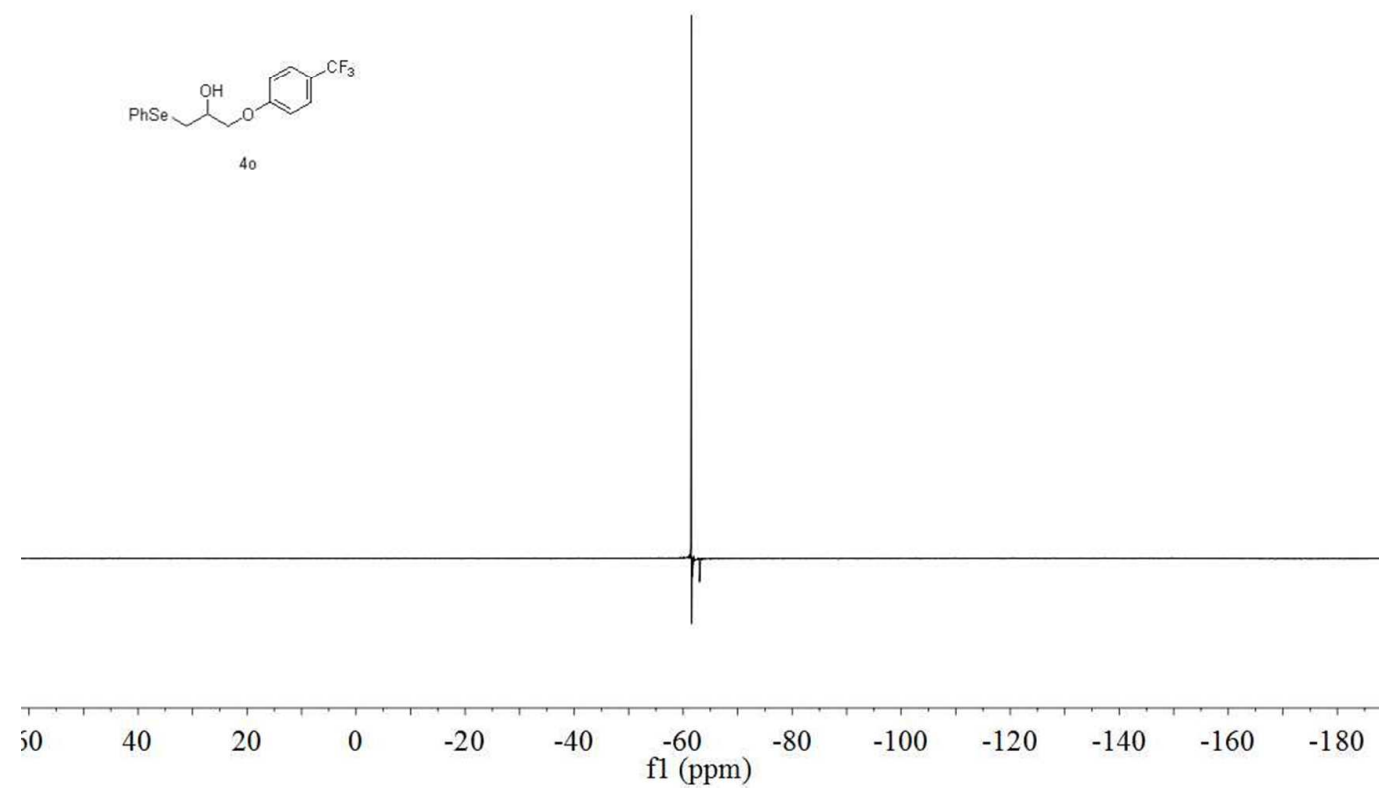

40 

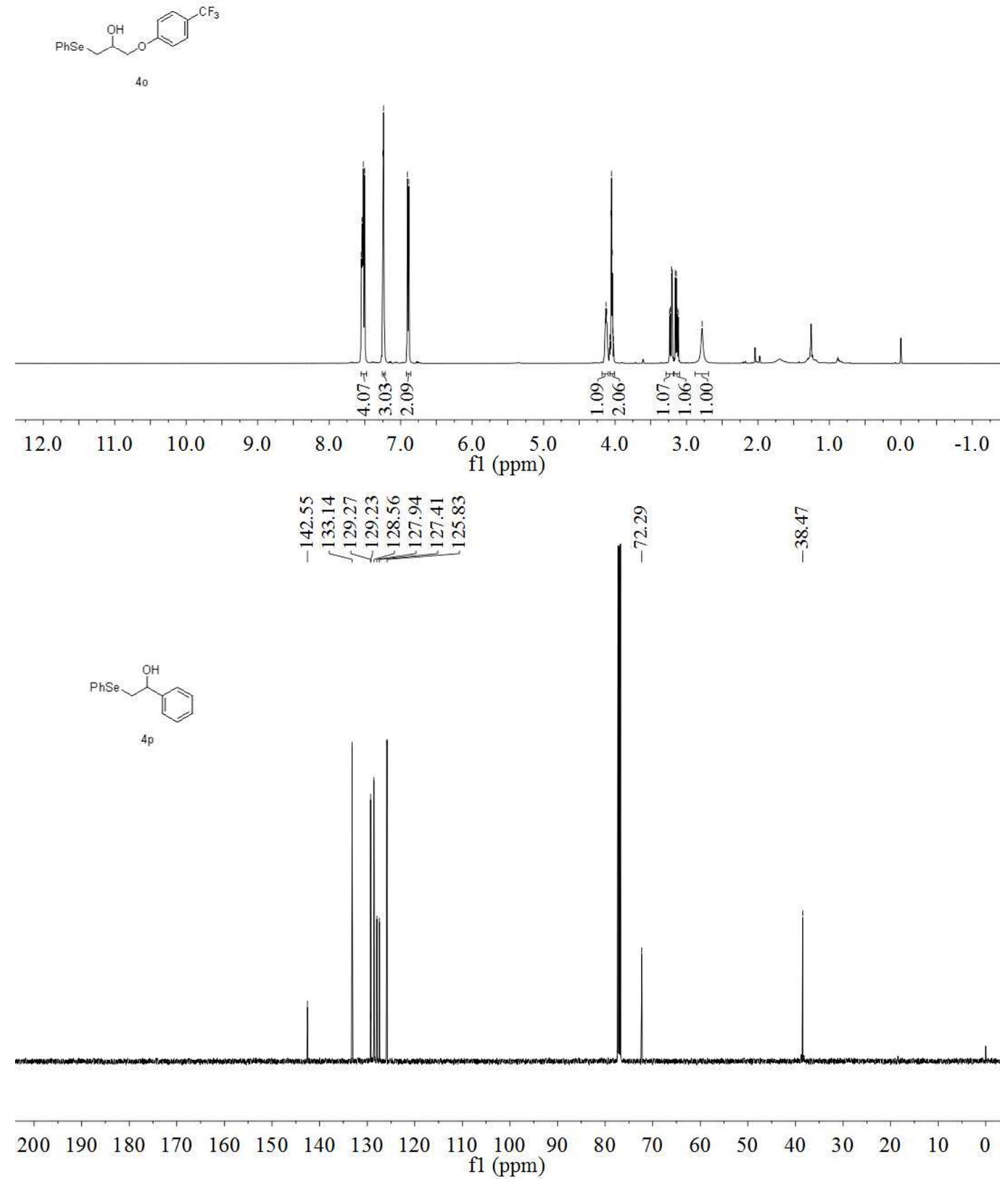

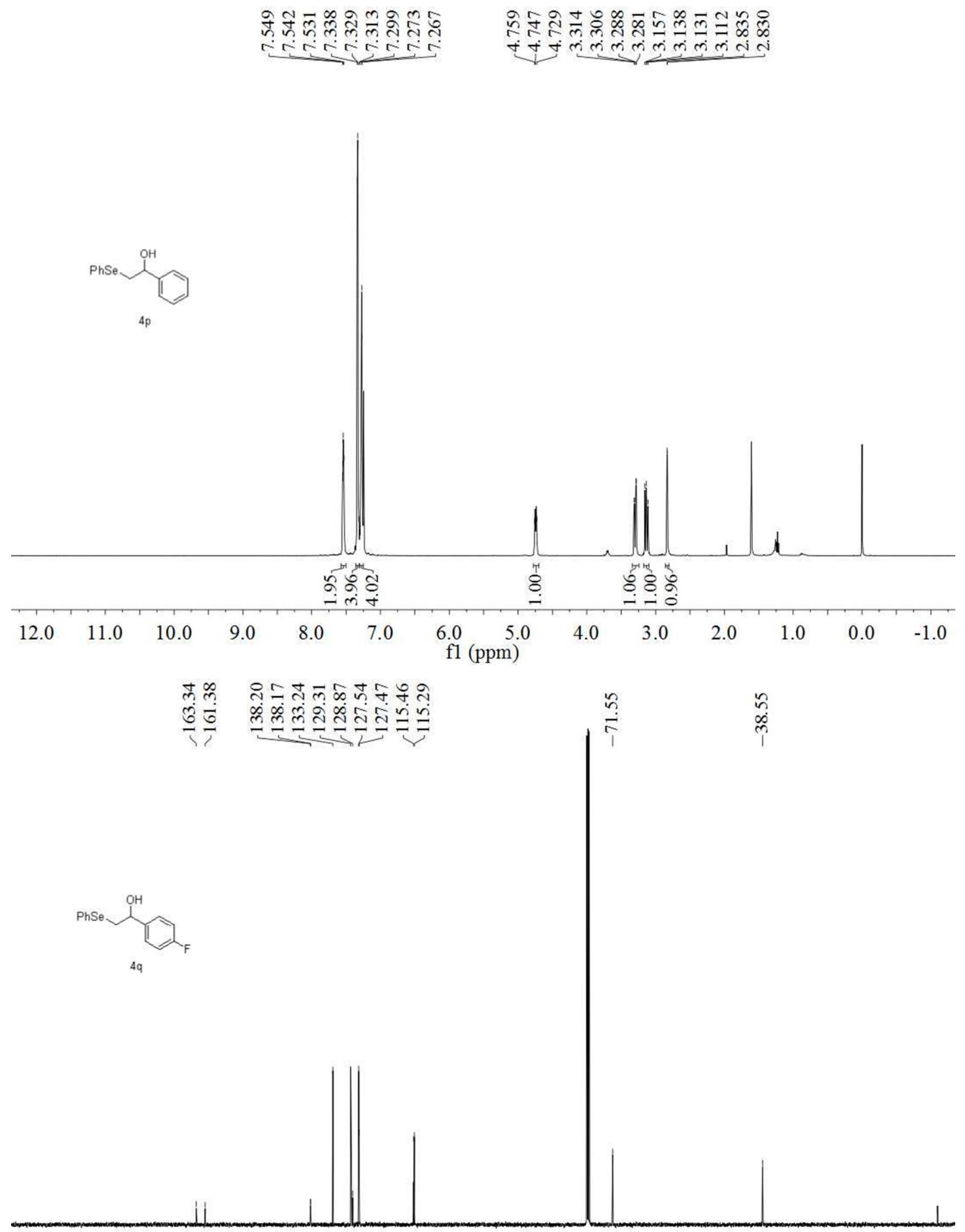

200

$\begin{array}{lll}190 & 180 & 170\end{array}$

$\begin{array}{llll}160 & 150 & 140\end{array}$

130120

110100

f1 (ppm) 


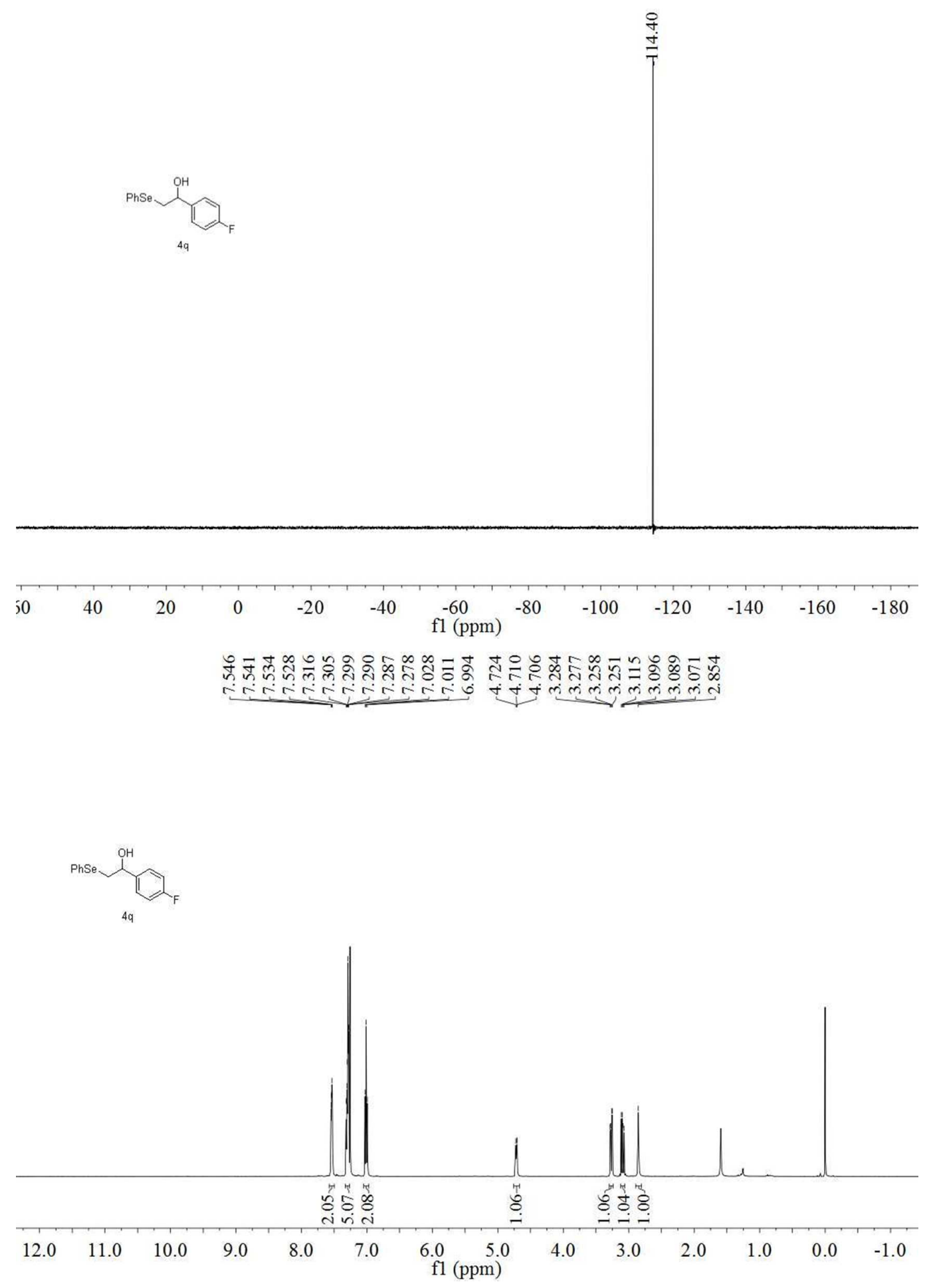




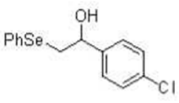

$4 \mathrm{r}$

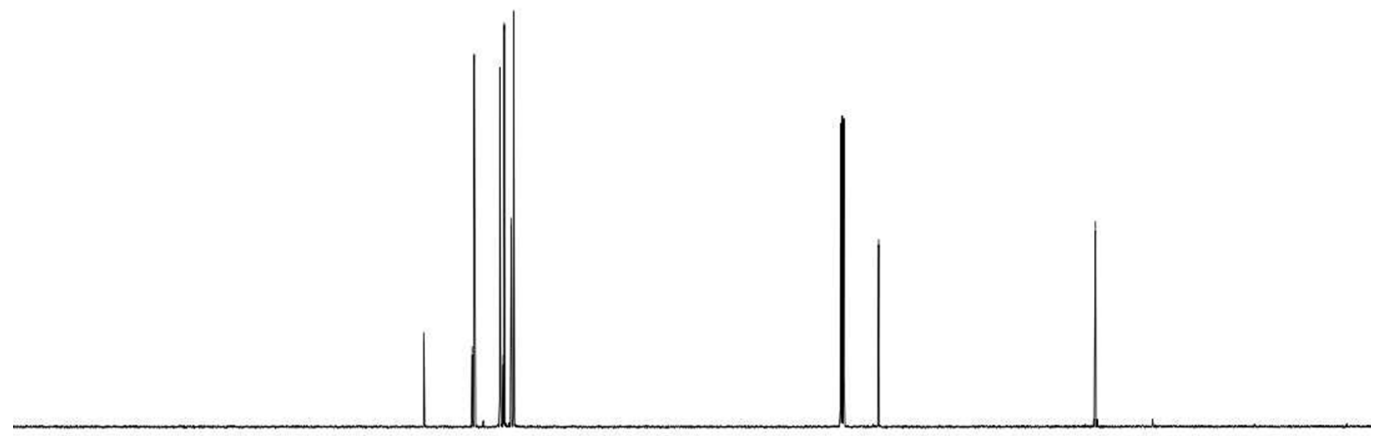

$\begin{array}{llllllllllllllllllll}200 & 190 & 180 & 170 & 160 & 150 & 140 & 130 & 120 & \begin{array}{c}110 \\ \mathrm{fl} 1(\mathrm{ppm})\end{array} & \begin{array}{c}100 \\ (\mathrm{ppm})\end{array} & 80 & 70 & 60 & 50 & 40 & 30 & 20 & 10 & 0\end{array}$

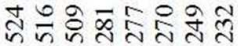

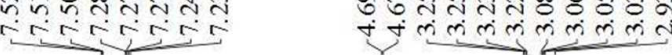
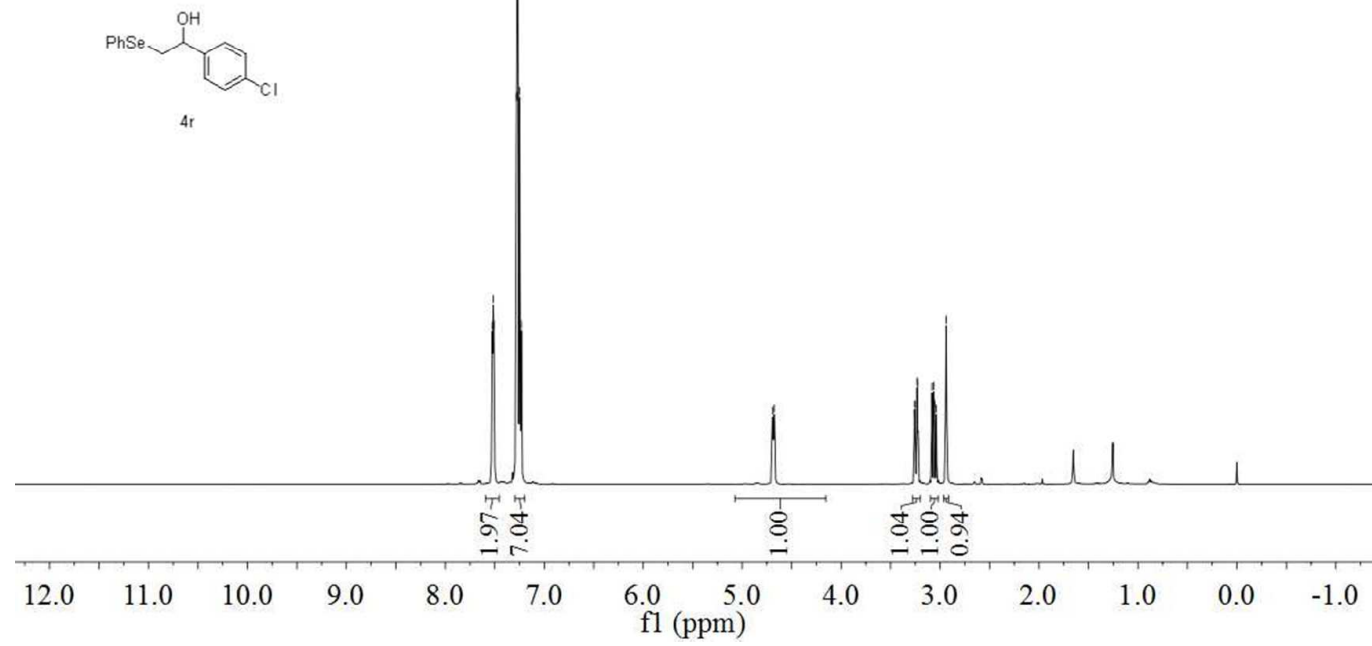


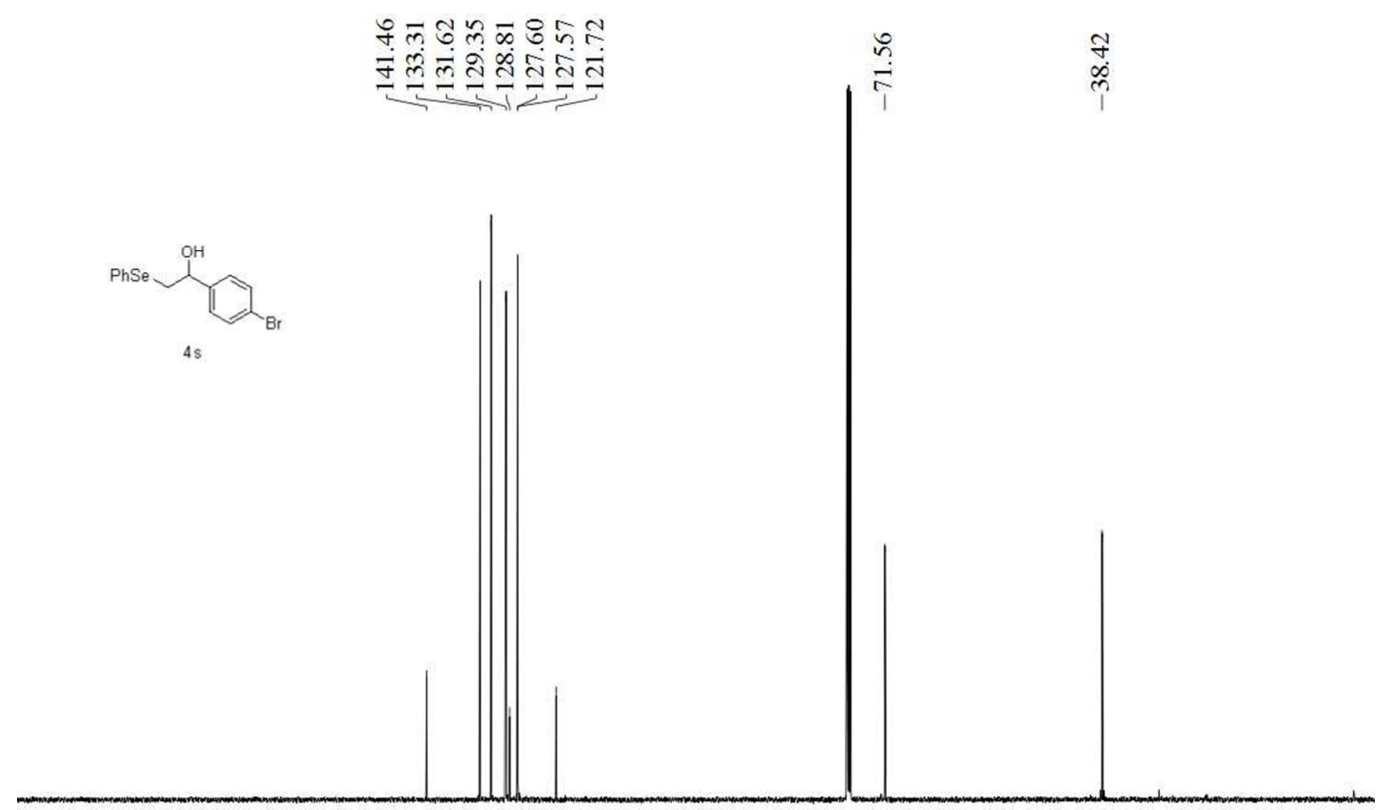

$\begin{array}{lllllllllllllllllllll}200 & 190 & 180 & 170 & 160 & 150 & 140 & 130 & 120 & 110 & 100 & 90 & 80 & 70 & 60 & 50 & 40 & 30 & 20 & 10 & 0\end{array}$

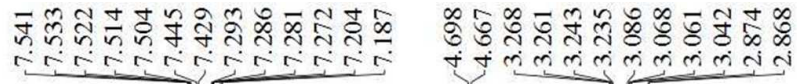
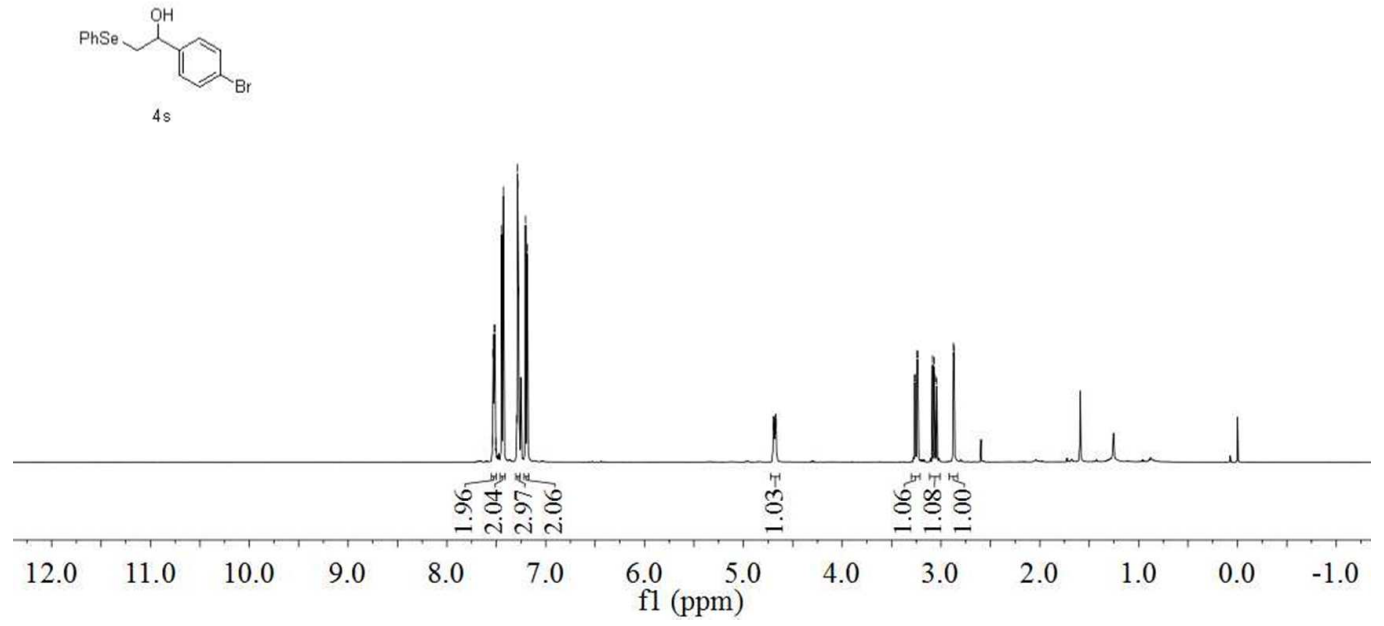

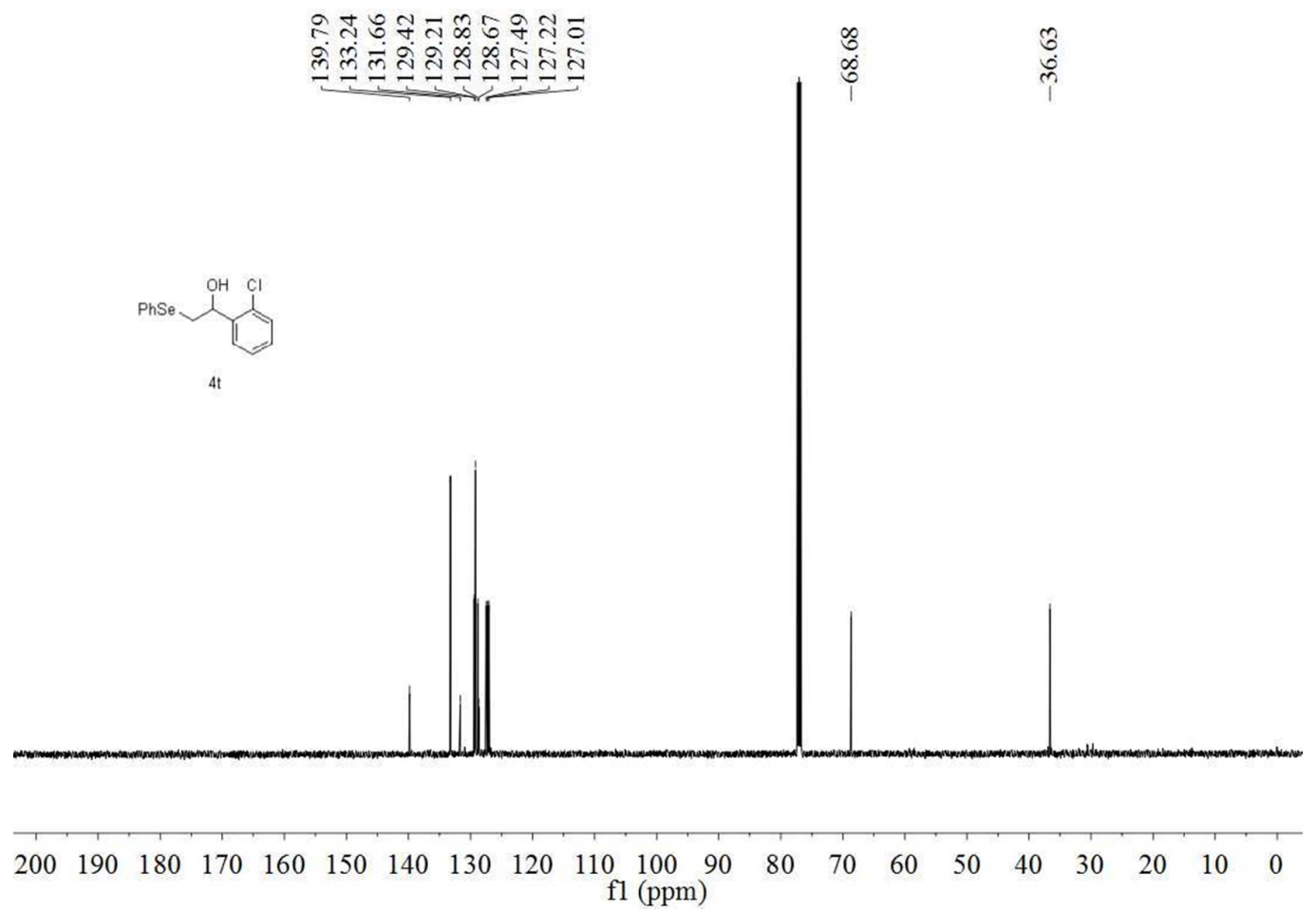

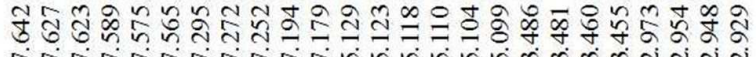

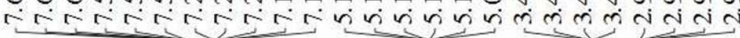

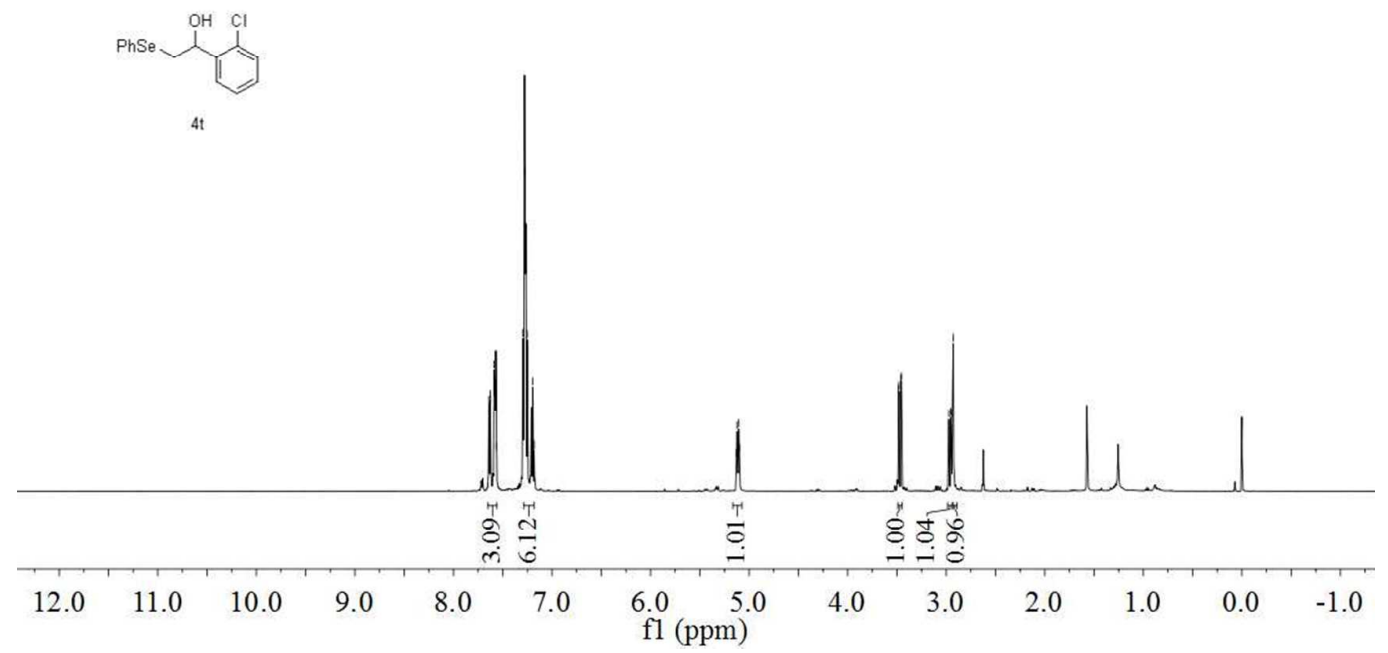


<smiles>OC(COCc1ccccc1)Cc1ccccc1</smiles>

4u

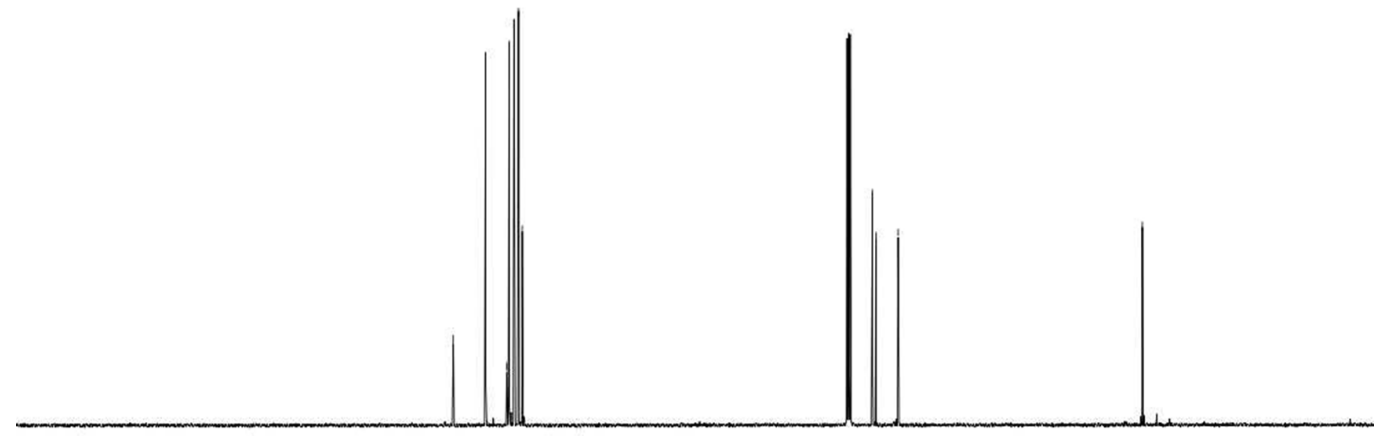

$\begin{array}{lllllllllllllllllllll}200 & 190 & 180 & 170 & 160 & 150 & 140 & 130 & 120 & 110 & 100 & 90 & 80 & 70 & 60 & 50 & 40 & 30 & 20 & 10 & 0\end{array}$

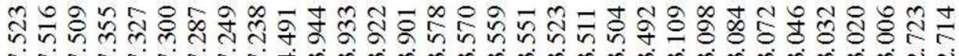

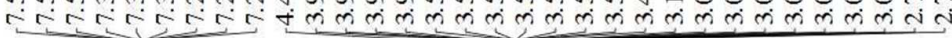

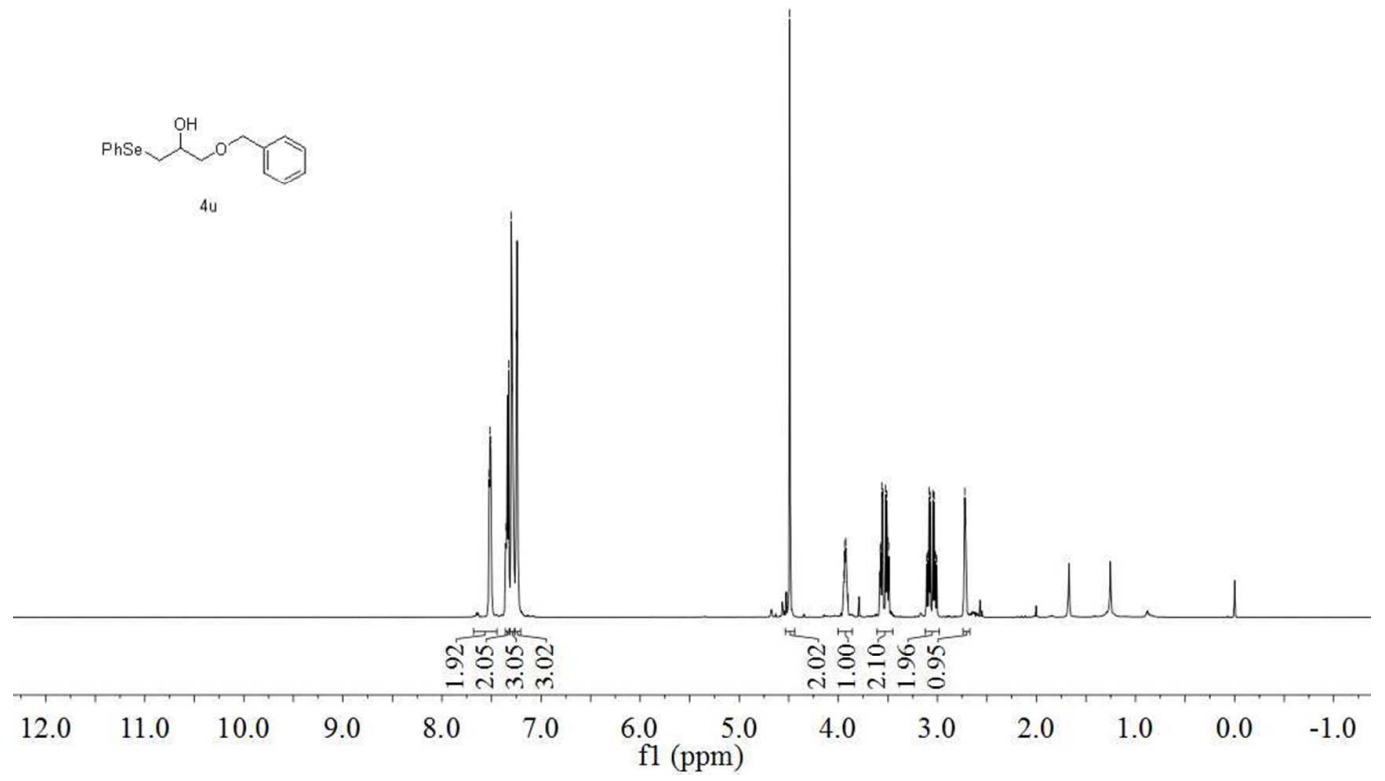




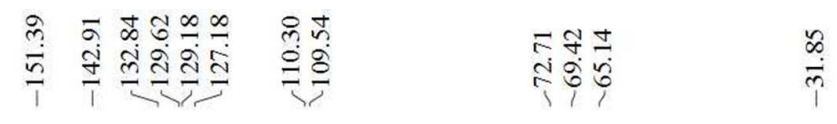
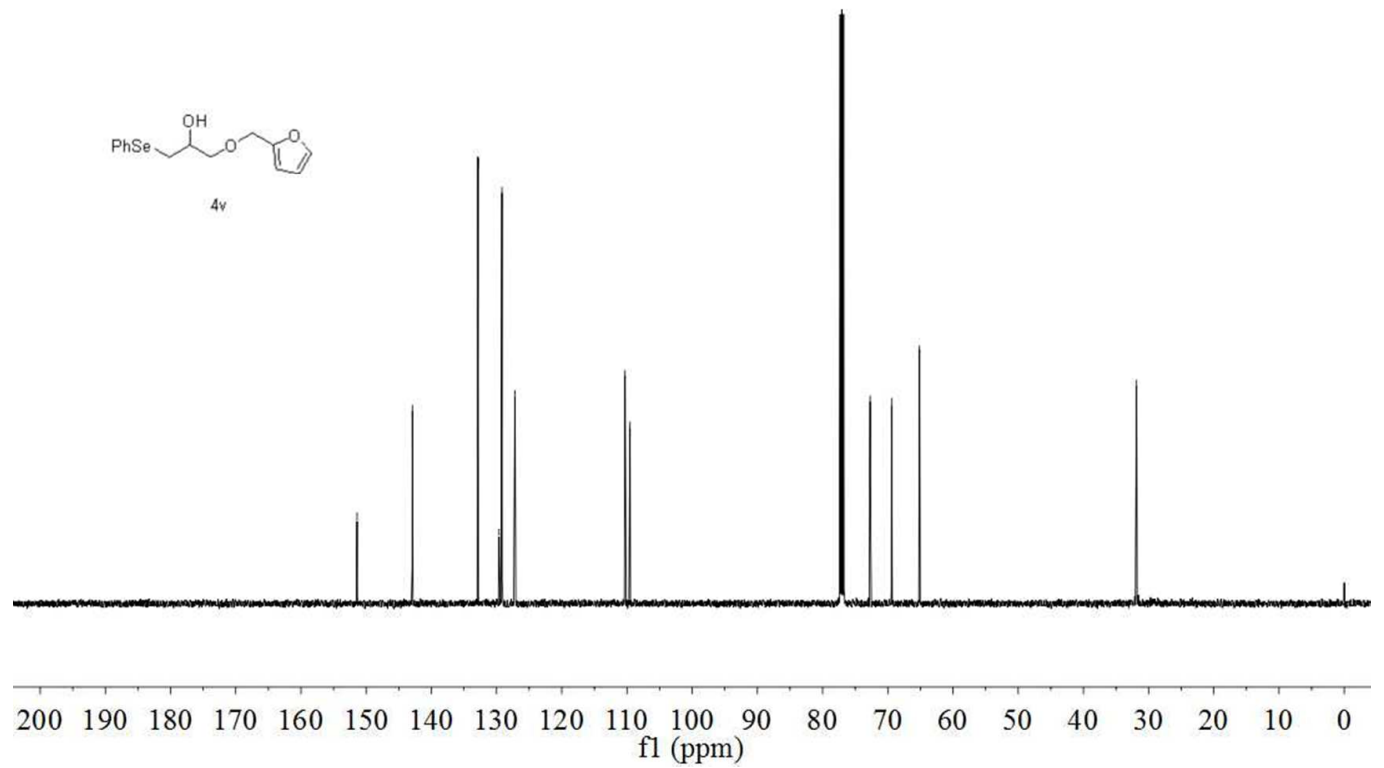

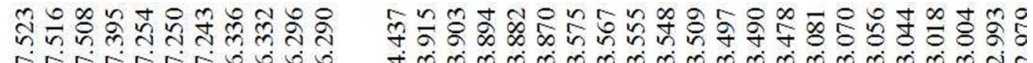

एरिए人

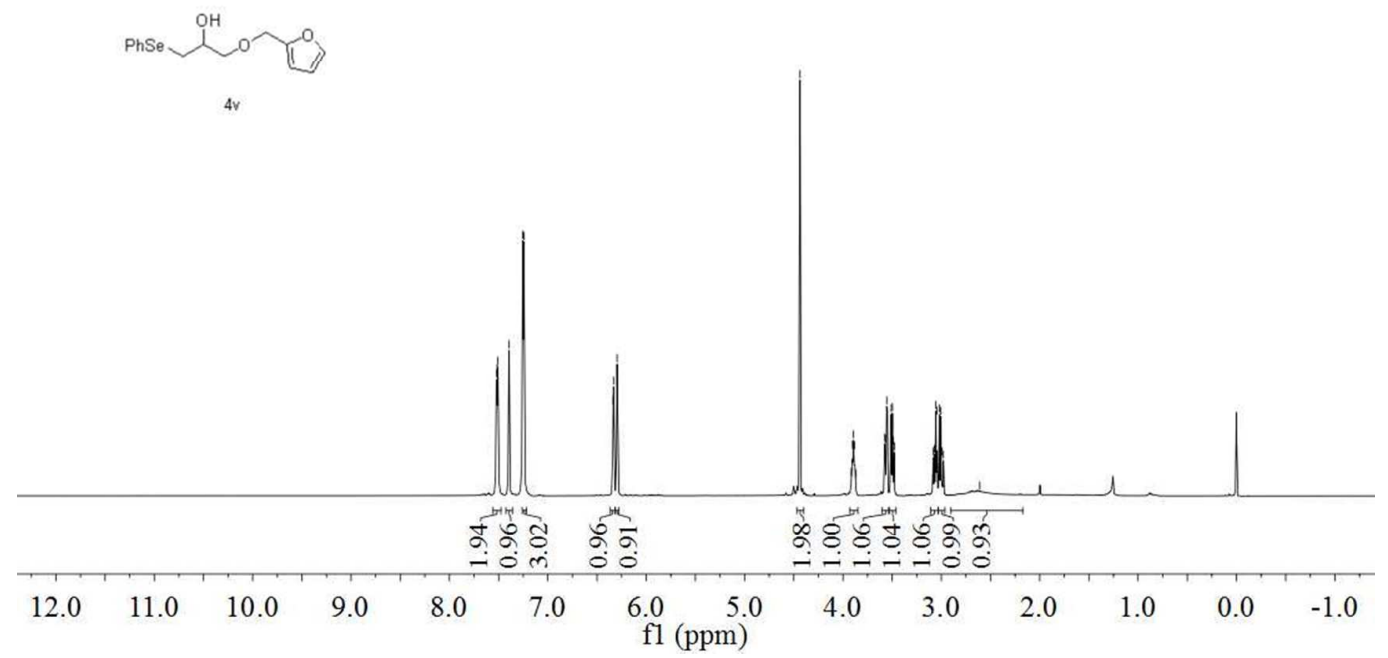

